Portland State University

PDXScholar

6-7-1996

\title{
An Organizational Profile: Members' Understanding of Discrimination
}

Debra Cay Hornibrook

Portland State University

Follow this and additional works at: https://pdxscholar.library.pdx.edu/open_access_etds

Part of the Speech and Rhetorical Studies Commons

Let us know how access to this document benefits you.

Recommended Citation

Hornibrook, Debra Cay, "An Organizational Profile: Members' Understanding of Discrimination" (1996). Dissertations and Theses. Paper 5292.

https://doi.org/10.15760/etd.7165

This Thesis is brought to you for free and open access. It has been accepted for inclusion in Dissertations and Theses by an authorized administrator of PDXScholar. Please contact us if we can make this document more accessible: pdxscholar@pdx.edu. 


\section{THESIS APPROVAL}

The abstract and thesis of Debra Cay Hornibrook for the Master of Science in Speech Communication were presented June 7, 1996 and accepted by the thesis committee and the department.

COMMITTEE APPROVALS:

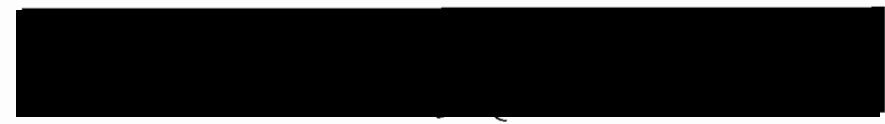

Devorah A. Lieberman, Chair

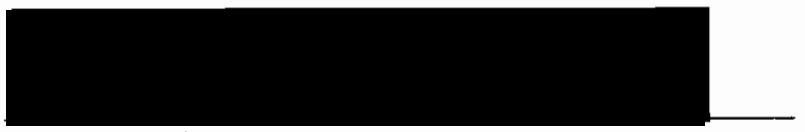

Susan Poulsen

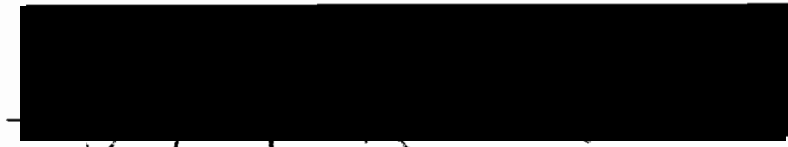

Gary Nave, Representative of the Office of Graduate Studies

DEPARTMENTAL APPROVAL:

Stephen A. Kosokoti, Chair

Department of Speech Communication

ACCEPTED FOR PORTLAND STATE UNIVERSITY BY THE LIBRARY

by on $\angle 2$ Lecmber 1996 


\begin{abstract}
An abstract of the thesis of Debra Cay Hornibrook for the Master of Science in Speech Communication presented June 7, 1996.
\end{abstract}

Title: An Organizational Profile: Members' Understanding of Discrimination

Cultural diversity in the United States is an issue of concern and organizations must now learn to function effectively with an increasingly diverse workforce. Since the history of U.S. organizations is a history of institutional discrimination against most ethnic and racial groups of people and the privileging of a dominant group, managing workforce diversity now constitutes one of the most difficult and important issues human resource professionals address.

This study is concerned with the issues of workforce diversity, most specifically with how organizational members understand and respond to discrimination, and the utilization of this understanding to discuss implications for diversity trainers. The study analyzed data from a workshop questionnaire administered to individuals who participated in a specific organization-wide diversity training program. Self-reported critical incidents were used in gathering data about organizational members' perceptions and understandings around discrimination. An analysis of short answer self-reported responses was conducted, followed by a analysis of themes by age, ethnicity and gender.

Emergent themes suggest that most organizational members encountered discriminatory incidents in the context of ongoing relationships, suggesting that it 
would be important for members to consider their responses in light of future consequences for the relationship. Since there are power dimensions inherent in many situations and there is a dominant cultural perception that conflict is destructive to relationships, responding to discriminatory situations may be perceived as a very high risk behavior.

Many participants had difficulty responding assertively at the time of the incident and reported feeling uncomfortable, angry, hurt, embarrassed or sad about the incident. Even after thinking about it, most were still limited in their ability to think of alternative responses.

Since most discriminatory incidents occurred in the context of ongoing relationships, diversity trainers and organizations may need to include a discussion of the power dimensions involved in addressing discrimination as well as address the overall U.S. cultural perception that conflict can only damage relationships. Diversity trainers as well as organizations may want to help their members frame conflict as opportunity for relationship development and discriminatory incidents as opportunity for learning. 


\title{
AN ORGANIZATIONAL PROFILE: MEMBERS' UNDERSTANDING OF DISCRIMINATION
}

\author{
by \\ DEBRA CAY HORNIBROOK
}

A thesis submitted in partial fulfillment of

the requirements for the degree of

\author{
MASTER OF SCIENCE \\ in \\ SPEECH COMMUNICATION
}

Portland State University 


\section{ACKNOWLEDGMENTS}

I would like to thank the members of my committee: Dr. Devorah Lieberman, Dr. Sue Poulsen, and Dr. Gary Nave. Each of you has supported me in this quest for completion and graduation, symbolized in a final product known as a thesis.

Special thanks to Paula Marie, Deborah Elam and Kathleen Lopez, my co-questers. 


\section{Table of Contents}

ACKNOWLEDGMENTS .............................................................

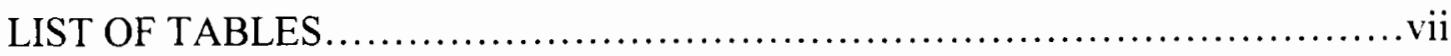

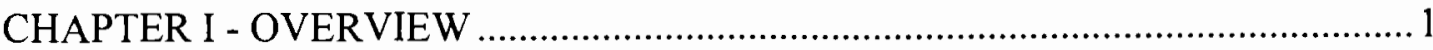

Discrimination and the Workplace

U.S. Workforce Conditions ........................................................................

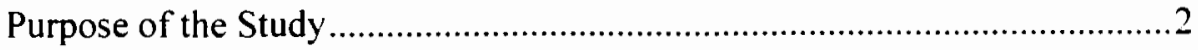

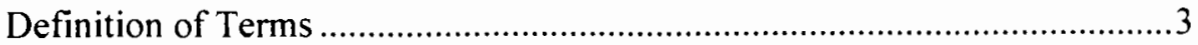

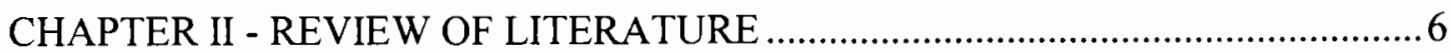

History: Organizations, Diversity and Discrimination ................................... 6

Rejection of Assimilation ...........................................................................6

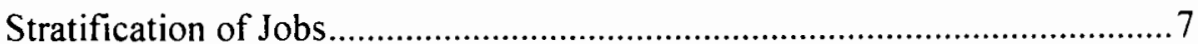

Focus on Workforce Diversity ....................................................................

Current Ways Organizations Address Diversity ............................................

History: Diversity Training......................................................................... 10

The Current Climate …………………………………….......................... 10

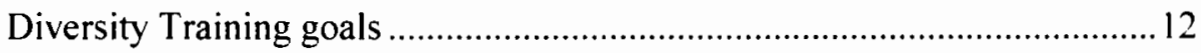

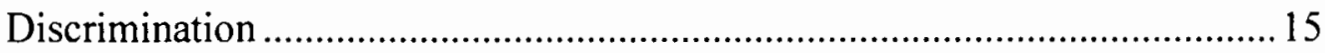

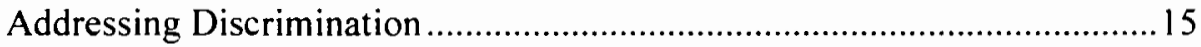

Definition - Prejudice and Discrimination ..............................................16

Responding to Prejudice .........................................................................

Structural Approach .............................................................................

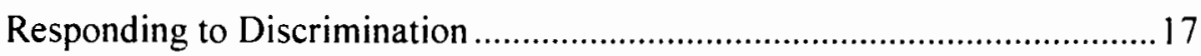

Two Stages of Responding to Discrimination ...........................................17

Identifying Stereotypes ........................................................................ 18 
Discrimination: Interpersonal Skills.........................................19

Responsible Language ..........................................................20

Assertive, Avoiding, and Aggressive Approaches …........................21

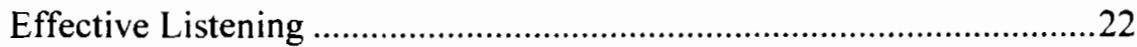

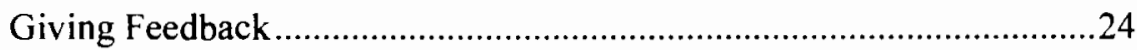

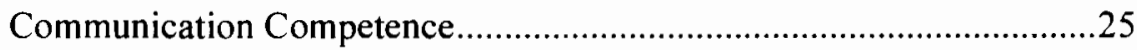

Supportive Climate Building .......................................................25

CHAPTER III - RESEARCH DESIGN, DATA COLLECTION, ...........................30

AND DATA ANALYSIS PROCEDURES ..................................................... 30

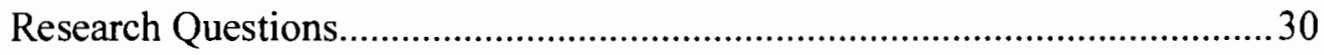

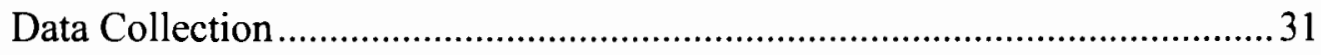

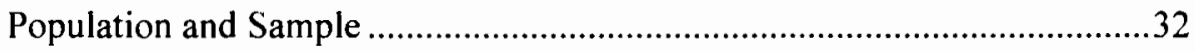

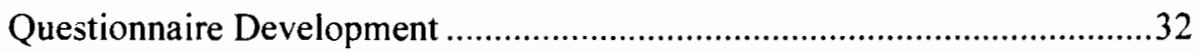

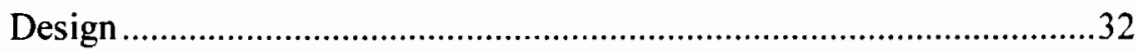

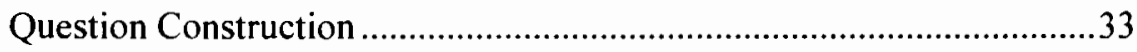

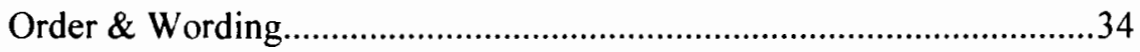

Confidentiality and Questionnaire Administration .............................34

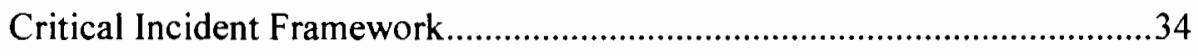

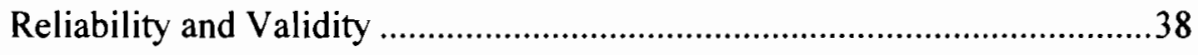

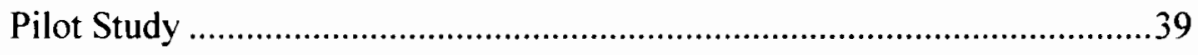

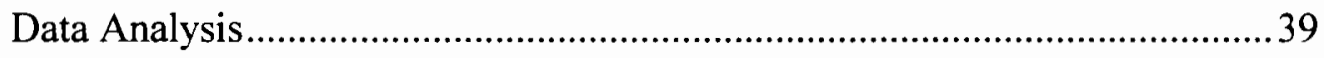

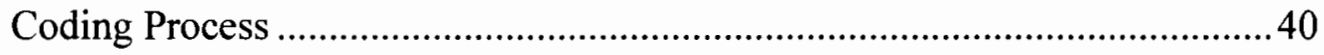

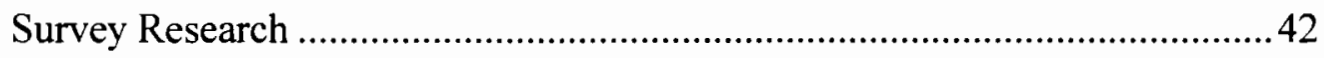

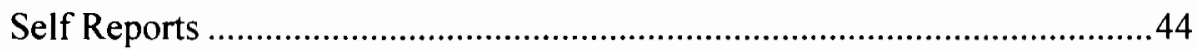

CHAPTER IV - RESULTS OF ANALYSIS ............................................... 45 
Demographic characteristics of sample ............................................... 45

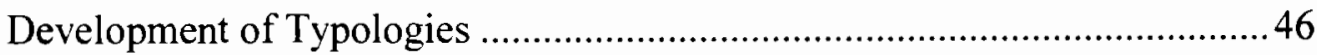

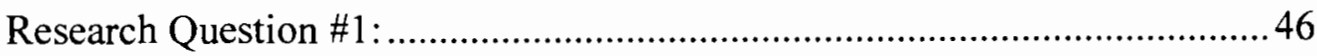

What were the situations identified by organizational members as

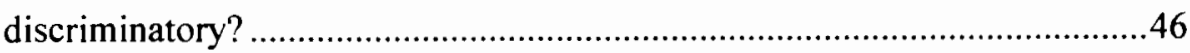

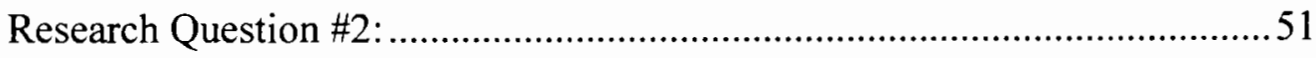

How do the organizational members manage discriminatory

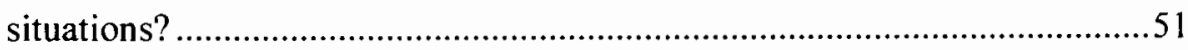

Research Question \#3: ................................................................ 54

What were the individual's later responses to the situations? ......................54

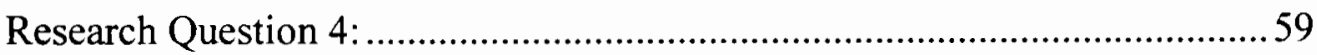

What did members report they could have said or done differently?..........59

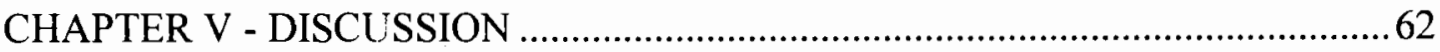

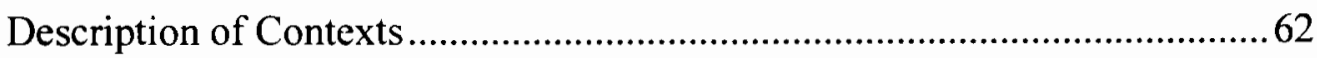

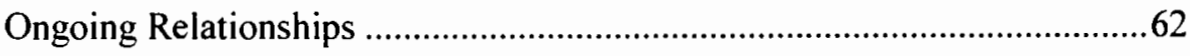

Discrimination Reported Less Often in Home or with Friends...................63

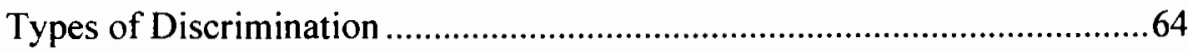

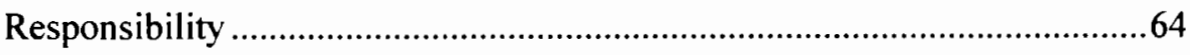

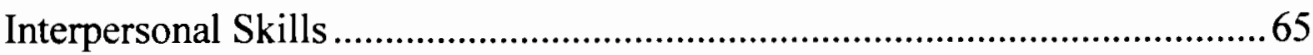

Relative Ability to Identify and Analyze Discriminatory Situations ...........65

Conflict or Discrimination as Opportunity...........................................67

Managed the Situtation - Assumptions and Responses.............................69

Assertive Responses Needed ............................................................ 70

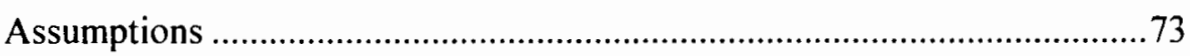

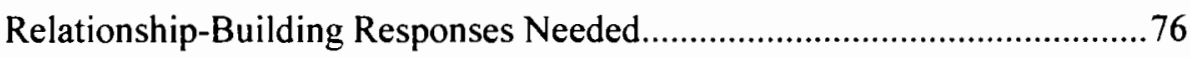


What Might Have Respondents Done Differently .....................................77

Cultural Difference in Channel Preference ……………………………........78

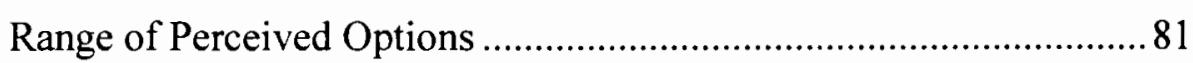

Literature Review: Gap Related to the Structural Approach............................. 83

Implications for Organizations and Diversity Trainers .................................. 85

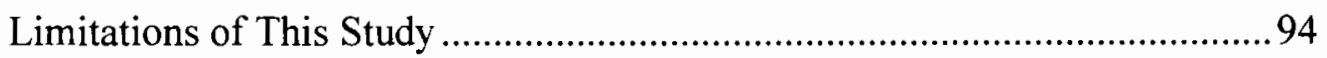

Implications for Future Study ................................................................... 94

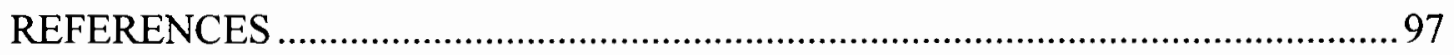

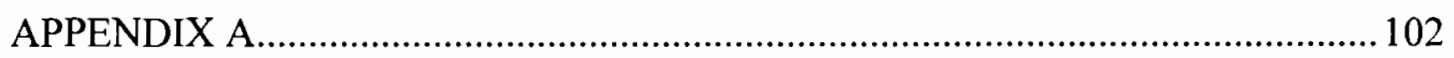

Diversity Questionnaire - Workshop questionnaire ...................................... 103

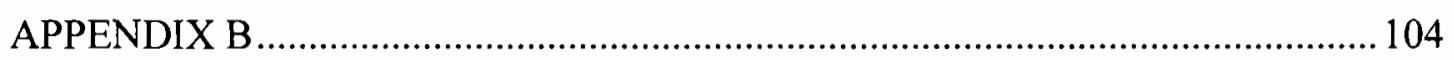

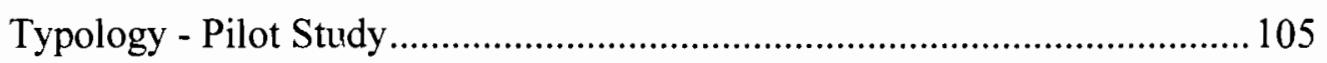

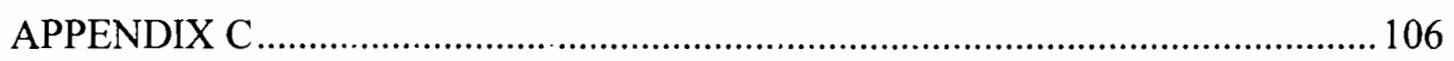

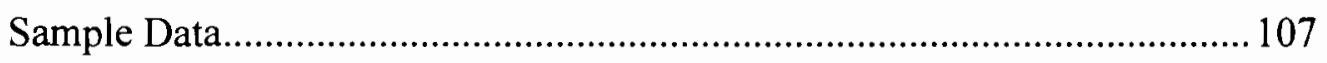

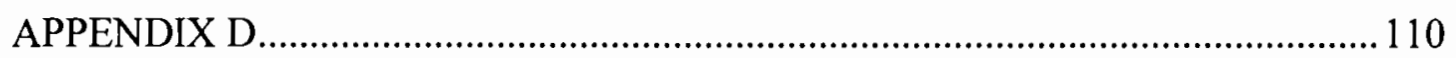

Description of the Diversity Training Program Analyzed in this

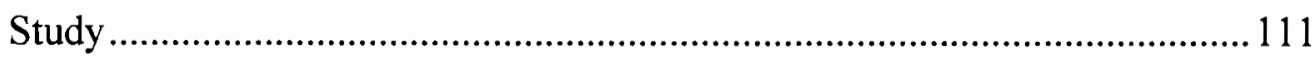




\section{List of Tables}

Table

Page

I Communication Choices and Orientations

II Demographic Characteristics

III Typology - Research Question \#1

IV Situations

V Description of Incident

VI Type of Discrimination by Setting

VII Typology - Research Question \#2

VIII Management of Discriminatory Situations 52

IX Typology - Research Question \#3 55

X Thoughts and Feelings About the Situation 58

XI Typology - Research Question \#4 59

XII Said or Done Differently $\quad 60$

$\begin{array}{ll}\text { XIII Managed Situations } & 71\end{array}$

XIV Thoughts and Feelings about the Situation 73

XV Could Have Done Differently 79

XVI Summary of Themes and Implications 93 


\section{CHAPTER I - OVERVIEW}

\section{Discrimination and the Workplace}

World politics is entering a new phase in which the fundamental source of conflict will be neither ideological nor economic. The great divisions among people and the dominating source of conflict will be cultural. (Huntington, 1993)

\section{U.S. Workforce Conditions}

Cultural diversity in the United States is an issue of concern and is becoming increasingly significant. Marshal McLuhan"s now popular term "global village" is fast becoming an accurate description of today's world as modern technology and information systems, an expanding world population, and changes in the economic arena all contribute to increasing intercultural contact (Samovar \& Porter, 1991).

The U.S. is experiencing a considerable shift in cultural demographics and work force conditions. Goddaard outlines several of those conditions:

The population and work force are growing more slowly than at any time since the 1930's. The average age of the population and work force is rising, and the pool of young workers entering the labor market is shrinking. Minorities are representing a larger share of new entrants into the labor market, and immigrants compose the largest share of new entrants into the labor market. $(1989$, p. 67)

Goddaard goes on to say that between now and the year 2000, nearly two-thirds of the U.S. labor force entrants will be women and $29 \%$ will be non-Caucasians. He summarizes by saying, "non-Caucasians, women and immigrants are projected to make up more than five-sixths, or $83 \%$ of the new additions to the work force between now and the next century, although they constitute only about half of it today" (p. 68). The combination of all these factors points to the importance of fully utilizing immigrant and diverse workers in the labor force. 
Organizations must now find ways to cope with an increasingly diverse workforce and the changing expectations of members of these diverse groups. In fact, managing workforce diversity now constitutes one of the most important issues human resource professionals address.

This is a difficult task because intercultural interactions commonly result in attitudes of ethnocentrism, or the tendency to assume that one's own way of life and culture are superior to others. Intercultural interactions also result in the generation of negative prejudicial attitudes and discriminative behaviors (Schaefer, 1988). It is also difficult because the history of U.S. organizations is a history of discrimination against most ethnic and racial groups of people and the privileging of a dominant group. According to Schaefer (1988, p 102), "discrimination is a widespread phenomenon in the United States. More significantly it is found in institutional discrimination...." In the context of workforce diversity, this study is concerned with 1) how organizational members understand and respond to discrimination, and 2) utilizing this understanding to discuss implications for organizational and diversity trainer policy and programs.

\section{Purpose of the Study}

Organizations are currently struggling to address workforce diversity and discrimination issues through a variety of policies and approaches with goals of helping people of diverse cultures work more productively and comfortably with each other and to better utilize company human resources. Diversity training is a current approach to meeting these goals. "Diversity training" is offered in organizations and while there is a great deal of.intercultural and cross-cultural research, there are few studies that assess the impact of diversity training in organizations. There are also few studies that focus attention on the discursive practices of discrimination or that identify organizational variables which may influence discrimination at the interpersonal level. 
Understanding organizational member's current perceptions and understandings of discrimination may prove useful to diversity trainers and to organizations as they make decisions about how best to address workforce diversity issues.

This study analyzes data from a workshop questionnaire administered to individuals who participated in a specific organization-wide diversity training program. This workshop questionnaire asked participants about their perceptions and experiences around discrimination. This study reports members' understandings around discrimination The researcher utilized self-reported critical incidents in gathering data and conducted a content analysis of short answer self-reported responses followed by an analysis of themes by age, ethnicity and gender.

The purpose of this study is to provide an organizational profile of members' current understandings around the issue of discrimination and, based upon relationships between demographic variables of gender, age and ethnicity and emergent themes, discuss possible implications for diversity training. In addressing the purpose, the following research questions are asked:

1. What were the discriminatory situations identified by organizational members?

2. How did the organizational members manage discriminatory situations?

3. What were the individual's follow-up responses to the situations?

4. What did members report they could have said or done differently? The subsequent literature review will provide a history of diversity in the workplace, review the most recent approach to addressing workforce diversity, diversity training, review the issue of discrimination, and review responses to discrimination. 


\section{Definition of Terms}

This study draws upon literature from several related areas to discuss training about cultural diversity. Educational scholars and trainers use a variety of terms in relation to cultural differences. There are different contexts and goals that govern choice of terms and while a number of definitions are available, the following have been selected as being most appropriate for this study.

\section{Diversity Training}

Gordon (1992) suggests a definition of diversity training by pointing out that "the prime objective of a diversity campaign is to help organizations fully realize the potentials of all their workers by promoting the synergistic cooperation of people from various backgrounds" (p. 26).

\section{Intercultural Communication}

Samovar \& Porter (1991, p. 316) define intercultural communication as "communication between people whose cultural perceptions and symbol systems are distinct enough to alter the communication event."

\section{Co-culture}

Samovar \& Porter (1991) describe members of co-cultures as "individuals and groups of people who, while living in the dominant culture, [have] dual membership in yet another culture (p. 72)."

\section{Multiculturalism}

Pusch (1979) defines multiculturalism as "that state in which one has mastered the knowledge and developed the skills necessary to feel comfortable and communicate effectively (1) with people of any culture encountered; and, (2) in any situation involving a group of people of culturally diverse backgrounds." 


\section{Cross-cultural training}

Pusch (1979) defines cross-cultural training as "a method developed to enable people to better manage, consciously and deliberately, the contact and interaction of culturally different groups and individuals" ( $p$ 86). Cross-cultural training usually refers to training for people who will live with, visit or work in another culture.

\section{Discrimination}

Schaefer $(1988$, p. 92) tells us that "discrimination is the denial of opportunities and equal rights to individuals and groups because of prejudice or for other arbitrary reasons."

As these definitions indicate, there are many contexts in which intercultural communication-related goals are addressed through a combination of education and training. Although this study focuses on organizational members' understandings of discrimination and the implications for diversity training, many of the methods, approaches, goals and values overlap with the literature in the related areas mentioned in the definition of terms. 


\section{CHAPTER II - REVIEW OF LITERATURE}

\section{History: Organizations, Diversity and Discrimination}

To discriminate against someone simply because he or she has a different color skin, prays to a different God, or speaks a different language diminishes the best that is in all of us (Samovar \& Porter, 1991, p. 15).

\section{Rejection of Assimilation}

The U.S. has experienced global immigration and has long been understood as a "melting pot." Traditionally, people of different backgrounds were expected to assimilate into the dominant culture and shed their distinguishing cultural accents, traditions and beliefs as quickly as possible in order to become "Americanized." The metaphor of the melting pot, however, is no longer satisfying to many. New metaphors such as "salad" or "stew" are emerging (Thomas, 1990) which indicate a wish for retention of distinguishing characteristics and signaling a time for recognizing difference.

Groups of people who live within a dominant culture but who are also members of another culture, called co-cultures (Samovar \& Porter), are experiencing an emerging cultural awareness and a resulting revaluation of the beliefs, values and traditions that inform each culture. Almquist (1989) explains that:

Historically, the major racial groups were geographically distant from one another, with blacks concentrated in the Southeast, Mexican-Americans-as the largest Hispanic group - in the Southwest, and Asians on the west coast. (p. 150)

As the geographic separation of groups diminish, contact and group identity increases along with cultural awareness, which is then reflected in current trends. Homosexuals are "coming out of the closet;" African-American cultural pride can be seen in current MTV, television and movies; women are pushing to break through the "glass ceiling;" people who have disabilities are increasingly seen in advertising and as television 
stars; and feminism is challenging the current patriarchal system from several directions. When talking about diversity and women in the U.S., Almquist (1989, p. 151) says: "Today, we find ... increasing activism in both minority group and feminist movements, increasing efforts to understand and transcend barriers of race, gender, and class." As Samovar and Porter (1991) posit:

Co-cultures and groups such as Native American, homosexuals, the disabled, the poor, the elderly, blacks, and women want[ed] a new recognition. Many were no longer willing to wait passively for admission into the dominant culture. ... In the coming years we can also expect demands for equal rights to increase from the growing population of co-cultures. (p. 11, 304)

Hall (1981, p. 7) substantiates Samovar and Porter's assertion when he says:

...a major and continuing source of frustration exists because the many gifts and talents of women, blacks, Native Americans, Spanish-Americans and others are not only unrecognized, but frequently denigrated by members of the dominant group.

Co-cultures and groups in the U.S. experiencing frustration expect equal rights and to be valued by the dominant culture. What does this mean for the U.S. work force?

\section{Stratification of Jobs}

The current U.S. organizational culture is a reflection of a history of privileging the dominant group and discriminating against devalued groups. Traditionally, minorities and women have served in the less-skilled and service jobs while white males have held professional and managerial positions. As Almquist (1989, p. 150151) tells us:

....Historically as well, the white majority used the different groups to fill different economic functions. Social definitions of race, ethnicity, and color were imposed on top of geographic distances and economic divisions

and Schaefer (p.85) reminds us that "women who try to enter roles traditionally reserved for men encounter prejudice and discrimination." 
However, the privileges once held predominantly by white males are now being challenged by minorities and women. For example, the number of black managers has increased to over one million in the last ten years (Samovar \& Porter). According to Samovar \& Porter, with a projected $84 \%$ of women working in the year 2000 , and racial and ethnic groups making up $45 \%$ of the population in 2050 , even "by the year $1995,75 \%$ of all those entering the work force will be women and minorities" (p. 14). As traditionally devalued co-cultures demand equal rights, turning a blind eye to discrimination is no longer an acceptable response. There is a necessity for recognizing discrimination and taking action when it is encountered.

\section{Focus on Workforce Diversity}

Both the sheer numbers of people of difference as well as their desire to be recognized have led to a condition which has forced attention to diversity in the work force and on issues concerning interaction between co-cultures and groups. Hence, difficulties encountered when groups with different beliefs, behaviors, traditions, etc. interact, are now being recognized by business. According to Reynolds (1992, p. 17) "it is vital for organizations to rethink organizational communication and personnel management in view of the growing diversity of the American workforce." Wigglesworth (1992, p. 53) suggests that "managing workforce diversity has become one of the most important issues in the field of human resources development."

So what does "managing workforce diversity" mean? Geber (1990) distinguishes between managing diversity and valuing diversity. She states that:

managing diversity can be accomplished in a relatively short time through a system of training sessions, subordinate feedback and performance appraisals coupled with rewards. ... Firms valuing diversity appreciate individuality and avoid pre-judging workers based on their cultural and ethnic backgrounds.... training employees to diversity encourages them to do something differently, while training them to value diversity encourages them to change their attitudes. [italics mine] (p. 24) 
Schaefer (1988, p. 57) tells us that prejudice is a negative attitude toward an entire category of people ... and involves attitudes, thoughts, and beliefs, not actions" while discrimination (p. 92) is: "the denial of opportunities and equal rights to individuals and groups because of prejudice or for other arbitrary reasons" and involves behavior. Thus, valuing diversity addresses prejudice while managing diversity addresses discrimination.

\section{Current Ways Organizations Address Diversity}

Due to the establishment of an Equal Employment Opportunity Commission and Affirmative Action, organizations must follow guidelines when it comes to hiring practices and treatment of employees. The first antidiscrimination act called Fair Employment Practices Commission occurred in 1943. The Executive Order 9931 ended segregation in the armed forces in 1948. The Civil Rights Act has been in place since 1964 and led to the establishment of the Equal Employment Opportunity Commission (EEOC), and Affirmative Action (AA). AA refers to "positive efforts to recruit minority group members or women for jobs, promotions, and educational opportunities" (Schaefer, 1988, p. 107) and was issued by executive order in 1963. Diversity training arose out of the need to address the lack of understanding around these issues and to increase the level of interpersonal and intercultural communication skills (Thomas, 1990). Shaefer (1988, p.20) tells us that "prejudice and discrimination result in several dysfunctions, including failure to use the resources of all the individuals which results in economic waste ... and group exclusion which is a barrier to communication." Diversity training is the most recent effort directed at addressing these issues.

Addressing diversity in organizations is a difficult undertaking because it entails approaching the issue at several levels, preferably simultaneously. Certainly 
one level involves a philosophical and ethical level in which the organizational leaders set the tone for addressing equity issues which then permeates the entire organizational culture. A second level involves the policies associated with hiring practices such as Equal Opportunity and Affirmative Action. A third level involves the degree of organizational policies established for addressing problems and complaints related to diversity. Another level involves the interpersonal relationships of the people in the organization, their level of awareness and how they respond when conflict around issues of difference arise. This study addressed the fourth level, describing organizational members' level of awareness and how they respond when faced with discriminatory situations.

\section{History: Diversity Training}

\section{The Current Climate}

Diversity training is one approach to increasing the ability of organizations to utilize all of their human resources. One way to understand diversity training is as an effort to move beyond the policy mode of addressing discrimination by instituting Equal Employment Opportunity (EEO) and Affirmative Action (AA) policy (Thomas, 1990). EEO policy addressed discrimination in hiring practices and the intention of Affirmative Action was to "eradicate prejudices that kept women and minorities from succeeding once they were hired" (Mobley and Payne, 1992, p. 46). As Thomas points out "the problem is making better use of their [minorities and women] potential at every level, especially in middle-management and leadership positions" $(1990, \mathrm{p}$. 108). 
There is a lack of widespread cultural/historical understanding of the reasons for EEO and AA, resulting in much anger and frustration in response to sometimes poorly implemented EEO and AA programs. Thomas explains the need to move beyond affirmative action "because affirmative action fails to deal with the root causes of prejudice and inequality and does little to develop the full potential of every man and woman in the company" (1990, P. 117).

Unfortunately, "people presumed that women and minorities would already know about biases and prejudices, so white men were the focus of the awareness training" (Mobley \& Payne, 1992, p. 46). Consequently, "many people still believe that the point of diversity training is to change white men" (Mobley \& Payne, p. 46). Thus, white men have been targeted as the oppressors and are tired of feeling guilty (Mobley \& Payne).

Diversity trainers have reacted by suggesting that diversity be a more inclusive term beyond race and gender and should include other differences such as age, educational background, etc. While many feel this broader definition of diversity makes diversity training more palatable, it also may obscure the original issues which prompted the focus on diversity.

Hence, diversity training operates in a politically and emotionally charged atmosphere in which people believe that their opportunities for economic survival are threatened and where "deep-seated biases and prejudices are emerging as a reaction to fast-paced social change" (Mobley \& Payne, 1992, p. 46). This context informs the goals, values and assumptions inherent in diversity training, among them, raising the level of awareness, reducing discriminatory behaviors, and developing skills in dealing with conflicts and misunderstandings likely to arise. Dealing with these tensions and dynamics requires well-designed programs. 


\section{Diversity Training goals}

The goals of diversity training are many and complex. Mobley \& Payne illustrate the complexity of diversity issues when they mention the confusion related to terminology, pointing out that "people confuse such terms as political correctness, diversity, multiculturalism, pluralism. equal employment opportunity, and affirmative action" (1992, p. 46). Thus, one goal of diversity training is to educate people about the many complex areas related to issues of diversity.

In addition to addressing the complex web of related ideas, the goals of diversity training must focus on several levels of human interaction. They include: attitudes toward diversity and intercultural communication; perceptions, awareness and knowledge regarding issues of diversity; skills and behaviors enacted when faced with situations related to diversity; and feelings about such situations and issues.

Delatte \& Baytos (1993), for example, suggest guidelines for diversity training which include "changing the company's existing organizational culture and its human resource systems" (p. 55) to support diversity concerns. Johnson (1992) suggests three approaches to diversity training: 1) awareness training 2) treating diversity as an organizational and management concern, with efforts focusing on what aids or obstructs diversity management and, 3) systematically reviewing company policies and practices to see how they can incorporate diverse needs and preferences.

Specific goals have been summarized by authors of texts which address training related to diversity. Pusch (1979, p. 96) lists the following goals of crosscultural training:

1. To expand cultural awareness; 
2. To increase tolerance and acceptance of different values, attitudes and behaviors;

3. To foster the affirmation of all cultures;

4. To develop intercultural communication skills;

5. To integrate cognitive and affective (or experiential) learning;

6. To prepare for effective personal adjustment to the stresses of intercultural experience;

7. To open avenues of learning and growth which inter- or multicultural experience makes accessible;

8. To develop the ability to seek information about the economic, political and social stresses and the aspirations of various culture or ethnic groups within a society and in the international arena.

Similarly, Brislin \& Yoshida (1994) developed a summary of beneficial outcomes from intercultural training. These outcomes may be related to thinking, knowledge, affective reactions and behavior. Brislin \& Yoshida (p. 166-170) list the following benefits or goals of intercultural training:

\section{Thinking and Knowledge}

1. Greater understanding and knowledge of host cultures from the point of view of the hosts;

2. An increased ability to recognize stereotyped conclusions and a decrease in the use of negative stereotypes;

3. Development of complex thinking about other cultures;

4. Development of "world-mindedness," an interest of events in various countries;

5. Ability to analyze critical incidents; 


\section{Affective Reactions}

6. Increase in feelings of self-confidence;

7. More enjoyment when among people of a different culture;

8. Feeling that have better relations with people of another culture;

9. Reduction in stress;

\section{Behavior}

10. Better interpersonal relations with people of another culture;

11. Hosts perceive trainee interacts with greater ease in host culture;

12. Increased sophistication in setting goals and composing solutions to problems when working with culturally diverse contexts;

13. Better job performance when working in culturally diverse contexts.

Particularly relevant to this study are goals related to the understanding and detection of discrimination and skills used to address discriminatory behavior. Mobley \& Payne address this goal of diversity training when they say "Diversity work can get at the heart of ...discriminatory assumption making (1990, p. 49)." Many hiring decisions are made based on assumptions that people most like themselves will fit in to "create the team cohesion that was critical to meeting the team's work goals" (Mobley \& Payne, p. 49). Diversity training challenges our societies propensity for sameness and familiarity and provides tools for dealing with discriminatory situations. (The goals of the trainer in this study are listed in the appendix entitled "Description of Diversity Training Program in this Study.")

One of the project objectives of the diversity training program in this study was to reduce intentional and unintentional discriminatory behaviors in the workplace. Consequently, the questionnaires analyzed for this study used the word 
"discrimination" to stimulate thought about a critical incident. Because

"discrimination" indicates a broad category of behaviors and attitudes that are addressed through diversity training and because it is a common word rather than jargon from a highly academic field, it provides appropriate stimulation for prompting thought about issues of diversity. This word communicates a great deal of information and may prompt people to think about situations in which diversity is an issue and may respond with strong or particular feelings, attitudes, and behaviors.

\title{
Discrimination
}

\section{Addressing Discrimination}

\begin{abstract}
Although overt racial and ethnic violence has lessened since the 1960s, we still see countless examples of subtle discrimination aimed at blacks, homosexuals, Asians, Hispanics, women, the poor, and the disabled. This negative behavior is not only contrary to American ideals but is harmful. It cripples both the holder of the prejudice and the target of such narrowness (Samovar \& Porter, 1991, p. 15).
\end{abstract}

Samovar and Porter (1991) demonstrate discrimination's overarching relationship to cultural diversity when they say, "Hence, throughout this book ["Communication Between Cultures"] we shall offer information about diverse cultures as well as a point of view aimed at reducing discrimination and prejudice (p. 15)." Samovar and Porter believe that "only by understanding and appreciating the values, desires and frustrations of other cultures can we shape a future that is fit for our generation and the next, and the next, and the next (p. 306)."

\section{Definition - Prejudice and Discrimination}

Schaefer (1988, p. 92) defines discrimination as "the denial of opportunities and equal rights to individuals and groups because of prejudice or for other arbitrary 
reasons." Winkelman (1993, p. 156) defines discrimination as "the negative and damaging behaviors people manifest against other groups as a consequence of their prejudice."

Shaefer (p. 57) tells us that "prejudice is a negative attitude toward an entire category of people.... and a prejudiced belief leads to categorical rejection." He goes on to say that prejudice is learned:

through friends, relatives, newspapers, books, movies, and television. The awareness that there are differences among people that society judges to be important begins at an early age (Shaefer, 1988, p. 60).

\section{Responding to Prejudice}

This study starts with the overt value judgment that society should work towards the reduction of prejudice and discrimination. In order to eliminate prejudice, it would be necessary to eliminate the causes - such as the desire to exploit others, fear of being threatened, and unacceptable personal failure (Schaefer, p. 81). Since personal therapy for everyone is not reasonable:

the answer would appear to rest with programs directed at society as a whole. Prejudice is indirectly attacked when discrimination is attacked. Despite prevailing beliefs to the contrary, you can legislate against prejudice; statues and decisions do affect attitudes (Shaefer, 1987, p. 81).

Hence, the EEO and AA approaches to addressing inequality, prejudice and discrimination. In addition, other successful ways of changing negative attitudes towards groups of people include mass media, education, intergroup contact, and working together towards a common goal (Shaefer, 1988). Formal education has been associated with racial tolerance, and teaches people to qualify statements and question rigid categories. While these behaviors may not directly reduce prejudice, a more considered use of language and a reassessment of categories and labels contributes to a 
more valuing and open climate. Diversity training workshops take the approach of education and providing interpersonal tools for confronting and addressing prejudice and discrimination.

\section{Structural Approach}

The structural approach to understanding the dynamics of discrimination suggests that societies develop social norms which encourage or discourage tolerance. The current economic and social ordering structure of Western cultures is founded upon the dynamic of competitiveness and a win-lose understanding of how the world works (Schaefer, 1988). As long as different groups view life as a zero-sum game in which the gain of one person or one group automatically results in a loss for another person or group, racism is the structural result (Schaefer, 1988). Thus, a social climate develops which may encourage prejudice and discrimination.

\section{Responding to Discrimination}

\section{Two Stages of Responding to Discrimination}

Lalonde and Cameron (1994) observe that the literature on research in responses to discrimination suggest that a response to discrimination includes two stages:

a) the acknowledgment that discrimination has indeed occurred, and

b) an analysis of the situation in order to determine which strategy of action, if any, to adopt.

Lalonde and Cameron have found that people know that discrimination occurs and may be aware that members of their own co-culture experience discrimination, yet they do not often identify individual instances of discrimination in their own lives. 
Lalonde and Cameron ( $\mathrm{p} 281$ ) suggest that "one challenge to future research is to identify the conditions that bring about an acknowledgment of personal discrimination when it occurs." This may be related to the breadth of communication knowledge needed to specify the behaviors that indicate that discrimination has occurred.

\section{Identifying Stereotypes}

Stereotypes are "exaggerated images of the characteristics of a particular group (Shaefer, 1988, p. 22)." Stereotypes often arise from a kernel of fact, but then become distorted or exaggerated. In addition, the generalizations made about different groups are often faulty. People engage in ethnocentrism, observing traits or behaviors and judging them according to their own cultural orientations. According to Korzybski, people often take an intensional orientation (1933), believe the stereotyped labels given, and ignore evidence to the contrary. As Schaefer points out:

The self-fulfilling prophecy adds to the stability of stereotypes. The dominant group creates barriers, making it difficult for a minority group to act differently from the stereotype. It also applies pressure toward conformity to the stereotype. Conformity to the stereotype, although forced, becomes evidence of the validity of the stereotype.

People not only believe the stereotypes about other co-cultures, they tend to also believe stereotypes about their own co-culture.

Some evidence has been collected to suggest that even today people accept to some degree negative stereotypes of themselves. The labeling process becomes complete as images are applied and in some cases accepted by those being stereotyped" (Schaefer, 1988, p. 67).

Thus, part of the difficulty with stereotyping is that we don't allow people to act outside the stereotypes, a structural function which maintains the current social conditions. While functionalists point out that "the use of stereotyping promotes in- 
group solidarity," conflict theorists view stereotypes as "serving to maintain the subordination of people (Schaefer, 1988, p. 68)."

Discrimination: Interpersonal Skills

In writing about children, Derman-Sparks $(1989, \mathrm{p} 69)$ says: "discriminatory acts are one form of aggressive behavior, as hurtful as physical aggression, and should be immediately and directly addressed." This, of course, assumes that adults themselves have the skills to perceive, understand and address discrimination. As Nishishiba (1994, p.2) has pointed out, "how people react and behave when they encounter prejudicial or discriminatory acts .... is virtually unexplored."

This study asks questions of the members of one organization in an attempt to describe their skills in perceiving, understanding, and addressing discrimination. While there is certainly literature which helps people understand intercultural and cross-cultural interactions, and there is literature describing the social phenomenon of discrimination, the skills needed in confronting and responding to discriminatory acts come from the interpersonal communication, conflict management, and mediation literature.

The participants in this study were asked to think of a discriminatory situation and 1) describe what happened, 2) describe what they said or did, 3) describe what they thought about it, and 4) describe what they might have done differently. Their responses included their perceptions and levels of awareness of intercultural situations; their cognitive responses; and their behavioral communicative responses. The purpose of this study is to describe organizational members understandings of discrimination.

Organizational members could respond in ways that confront or encourage a reduction of prejudice and discrimination; or in ways that maintain or encourage prejudice and discrimination. The interpersonal communication, conflict and 
mediation, and intercultural literature reveal several important skills and themes in addressing discrimination.

Many of the general communication skills such as utilizing Gibb's categories for creating confirming climates, perception checking, paraphrasing, asking questions, using descriptive language instead of evaluative language, taking an assertive approach over an avoiding or aggressive approach, actively listening, using "I language" instead of "you language," etc. are all appropriate in addressing discrimination. Following is a summary of relevant interpersonal skills useful in confronting and addressing discrimination.

\section{$\underline{\text { Responsible Language }}$}

A common defense-provoking behavior is the use of evaluative or judgmental language. Judgmental language often contains an accusatory or blaming attitude, often described as "you" language (Adler \& Rodman, 1991). When using "you" language, the fault for personal reactions to an action is blamed on the other, as in "I can't believe you would say that" or " you are so insensitive."

"I" language, instead of judging the other person, describes the personal effect of the behavior or attitude (Adler \& Rodman, 1991). This response usually includes a description of the other person's behavior, an explanation of how the behavior affects the speaker and a report of the speaker's feelings, as in "when I hear that joke I get very upset because I think it degrades people." Thus, when using "I" language, one takes responsibility for one's own thoughts, one's feelings, and one's reactions rather than blame them on the actions of another. 
Assertive, Avoiding, and Aggressive Approaches

Mayer (1989, p. 39) tells us that "primary source of most major or destructive conflicts are (1) the avoidance of confronting, or expressing and working through, differences and (2) the need to be right." Mayer explains that avoidance is an understandable reaction since people seek to maintain stability and do so through maintaining their own comfort level. The feelings following a rupture of stability include discomfort, anxiety, ambiguity, uncertainty, and anger. In attempting to regain a sense of comfort and stability, people will often first "attempt to ignore the breach, saying it was nothing, apologizing without dealing with the underlying hurt, or perhaps hugging or shaking hands without real heart-felt contact (Mayer, p. 39." Mayer suggests some ways that people defend and practice avoidance including:

1. Telling one's self that there is not enough time to deal with the difference

2. Deciding that this little irritation isn't important enough to fret about

3. Figuring that "time will take care of it"

4. Practicing politeness, pretending tactfully that everything is ok

5. To call for "objectivity" or "rationality" - "Let's not get emotional" (meaning: "agree with my views")

6. Focusing on details

7. Diverting or smoothing over the issue

8. "Gunnysacking" or saving up grievances until, at some point, they all spill out no matter how unrelated to the trigger incident

In addition to maintaining stability, the "need to be right" is a second issue that contributes to avoidance. Mayer explains that, through the process known as the selffulfilling prophecy, or seeing what we expect to see, we may verify our own perception of events. He says that: 
once we formulate an idea or opinion about someone or something, if we don't prove it correct, we are either wrong or crazy. Either is very uncomfortable, so we will - usually unintentionally and unconsciously - set out to prove it true. Chances are we'll succeed. We will thereby stay blind-and 'right' (Mayer, 1990, p. 44).

Mayer comments that "sadly, most people will go to great lengths to be right, not to be wrong, to avoid criticism. We make ourselves right and thereby keep ourselves in the dark - and in conflict (p. 44)." In finding ourselves angry, offended, or hurt in relation to anther's behavior, and believing in the rightness of our own perspective, we may express ourselves by using evaluative language; blaming or judging the other person. Thus, we may engage in behavior that is aggressive or attacking. As explained above in regard to "you" statements, using evaluative language creates a defensive atmosphere. Open interchange between people is discouraged and a wall or barrier is created.

An alternative approach would be to engage in assertive behavior; directly and clearly expressing needs, thoughts, or feelings in such as way as to refrain from judging, dictating, or attacking the receiver's dignity (Adler and Rodman, 1991). An assertiveness attitude includes the belief that it is usually possible to resolve situations to everyone's satisfaction and the priority of maintaining the self-respect of all the people in the interaction. Behaviorally, assertiveness is accomplished through the use of descriptive language, and by utilizing "I" language to state feelings, beliefs, values, and preferences. Any inferences or judgments made are acknowledged as such and responsibility is taken for those inferences and judgments by using "I" language.

\section{Effective Listening}

One of the primary skills in addressing discrimination is that of listening. In order to identify a discriminatory incident and determine an effective response, the first step is to listen carefully and critically to the incident. Listening means to pay 
attention not only to the words that were actually said, but also to the nonverbal and relational messages in an interaction. This means listening with your eyes as well as your ears. Thus, one may "listen" to the communication messages implied in certain behaviors.

Listening is the key piece that comes before forming a response. The listening "frame" one uses to understand an interaction largely determines whether the response will be descriptive and questioning for example, or evaluative and controlling. Mayer (1989, p. 51.) says that true listening "is without judgment, preconceived notions, or desires to tell one's own story (p. 51)." Some of the more common barriers to effective listening include the following:

Ignoring: $\quad$ Refusing to listen to what the other person has to say. You may have had "button pushed" and turn off, or you may decide from the sender's appearance that you do not wish to hear what they have to say.

Reacting: $\quad$ Reacting with strong emotion to what was said (letting your buttons get pushed) and responding with judgmental language

Ambushing: $\quad$ Listening carefully to collect information with which to attack the other person

Forming a retort: Mentally forming and rehearsing your response rather than pay full attention to what the sender is saying

Discounting: $\quad$ Discounting the entire message if you find even one flaw

Closed Mind: $\quad$ Filtering the other's message through your own judgments, "shoulds" and "shouldn'ts" and discounting the message

The following responses encourage the development of a supportive climate:

Acknowledging the Acknowledging the other person through nonverbal recognition other person: and verbal recognition of their views and feelings. There is a widely held misconception that acknowledging means agreeing. 
It is possible to acknowledge a person's contributions, views and feelings without agreeing with their point of view.

Perception

Checking:

Questioning:

Paraphrasing:
Recognizing that the assumptions and inferences you make as a listener may not be accurate and asking for clarification. A perception check involves describing the behavior and your interpretations and then asking for feedback.

Asking sincere questions for clarification.

Paraphrasing helps to ensure that the message heard by the listener is the message intended by the sender. Paraphrasing involves summarizing in your own words what the person has just said. Paraphrasing involves summarizing both the content of the message and the feelings of the sender.

Acknowledging feelings is an important part of listening in a conflict situation. As

Mayer points out that if people appeal to rationality in an effort to suppress feelings: they ignore the fact that suppressing the expression of feelings usually precludes objectivity because the feelings will operate anyway to influence viewpoints and decisions, but outside of one's awareness. Feelings must be acknowledged for rationality or objectivity to be truly manifested

\section{Giving Feedback}

While listening, a person gives the speaker feedback reacting to what is said and telling the speaker the effect the speaker is having on the listener (DeVito, 1994). Ineffective feedback is:

- evaluative

- vague or general

- and does not honor the needs or values of the other person

Effective feedback is:

- descriptive

- specific

- and addresses the needs and values of both people 


\section{Communication Competence}

In order to deal effectively with a discriminatory incident, one must perceive a number of possible communication choices. The more a person knows about communication, the more likely it is the person will realize that there are a variety of possible ways to understand and respond to the incident. Communication competence refers to the knowledge of the social aspects of communication (DeVito, 1994). Increasing communication competence means having a broader range of communication options available from which to choose. The more alternatives a person can identify, the less trapped they may feel by the interaction.

\section{Supportive Climate Building}

Jack Gibb offers an effective framework for understanding the behaviors and attitudes that lead to the development of a supportive climate that enables people to feel safe and valued as well as the factors that lead to a defensive climate in which people feel devalued and defensive. Groups can create either supportive or defensive, safe or unsafe climates. The creation of a climate in which people feel the need to protect and defend themselves arises out of situations in which participants engage in the evaluation of others; attempt to control and utilize strategy to manipulate others; and respond with attitudes of indifference, superiority, or certainty. A defensive climate is one where participants feel judged and begin to protect themselves. They disclose only "safe" information that cannot be used against them. Resentment may build and resistance may go underground through strategies of noncooperation, covert manipulation, and passive resistance.

A supportive climate, on the other hand, is developed by using descriptive language instead of evaluative language; by taking a problem-orientation; by expressing spontaneously instead of manipulatively, and by employing attitudes of 
empathy, equality, and provisionalism. In a supportive climate, diverse opinions and approaches are supported and the climate engenders relationships of mutual trust and acceptance.

A special emphasis is placed on the skill of using descriptive language. Mayer points out the primacy of learning to use descriptive language when he says:

the need to express one's sense of being restricted, put down, rejected, insulted, overlooked, unappreciated, slighted, confused, hurt, betrayed, bored, manipulated, or any other pinch brings us to the first of the conflict management skills: learning to describe behavior rather than to attribute and describe motives $(1989$, p. 49)."

One of the difficulties with learning new communication skills can be remembering them in the midst of conflict situations when emotions are running high and people are feeling "on the spot." The following mnemonic devices (Lieberman, 1994) summarize several helpful sequences of key communication skills. Key communication skills in the mnemonic devices include describing behaviors, taking responsibility for thoughts and feelings, encouraging continued interaction through giving positive feedback and requesting feedback, identifying inferences and judgments, and understanding intercultural differences.

$$
D O E
$$

D escribe the interaction with specific descriptions of what you see and hear $\underline{\text { O wn }} \quad$ your feelings and thoughts by using "I" statements

E ncourage further communication by asking something like "what can we do so this doesn't happen again?" or "how can we meet both our needs here?"

\section{DI $V$}

The DIV mnemonic reminds users to distinguish between descriptions, inferences and value judgments. When making an inference or stating a value 
judgment, the speaker will elicit a less defensive response when "I" statements explaining how the speaker interprets the behavior and how the speaker feels about the behavior.

D escription reports the interaction using specific descriptions of what you see and hear

I nference tells what you think the interaction means

V alue judgment tells whether you think the interaction is good or bad, ethical or unethical, moral or immoral

$D U E$

In the face of this particularly difficult interpersonal or group situation in which a discriminatory behavior has been observed, Dr. Lieberman has developed a skill directly useful in intercultural situations called the DUE process. The DUE process encourages the speaker to remember that there may be different ways to understand an interaction and asks the speaker to examine the possibilities rather than jump to conclusions about the meaning of the interaction, the intention of the other person, assumptions about the character of the other person, etc.

D escribe the behavior using specific descriptions of the interaction $\underline{\mathbf{U}}$ nderstand the interaction by asking, either yourself, or the other person, if there might not be an intercultural difference at work in the interaction

E ncourage further communication by asking for feedback and keeping an open mind

All the preceding choices and orientations are summarized in the following table. 
Table I

Communication Choices and Orientations

\begin{tabular}{|c|c|}
\hline $\begin{array}{l}\text { Confronting and Discouraging } \\
\text { Discrimination }\end{array}$ & $\begin{array}{l}\text { Maintaining or Contributing to } \\
\text { Prejudice and Discrimination }\end{array}$ \\
\hline Responsible language - "I language" & Not Responsible - "You language" \\
\hline Assertive Approach & Avoidance or Aggressive Approach \\
\hline Encourage Feedback & Discourage Further Communication \\
\hline Supportive Climate Building & Defensive Climate Building \\
\hline Description of Feelings & Evaluation of Character \\
\hline Description of Behavior & Evaluation of Behavior \\
\hline Problem Orientation & Control \\
\hline Spontaneity & Strategy \\
\hline Empathy & Neutrality \\
\hline Equality & Superiority \\
\hline Provisionalism & Certainty \\
\hline Effective Listening & Ineffective Listening \\
\hline Acknowledging the other person & Ignoring \\
\hline Perception Checking & Ambushing \\
\hline Paraphrasing & Forming a retort \\
\hline Questioning & Closed Mind \\
\hline Giving Feedback & Giving Feedback \\
\hline It is descriptive & It is evaluative \\
\hline It is specific & It is vague or general \\
\hline $\begin{array}{l}\text { It addresses the needs and } \\
\text { values of both people }\end{array}$ & $\begin{array}{l}\text { It does not honor the needs or } \\
\text { values of the other person }\end{array}$ \\
\hline Communication Competence & Limited Perception of Alternative Choices \\
\hline Interpersonal Skills & \\
\hline $\begin{array}{l}D O E \text { - Describe, Own and Encourage } \\
D I V \text { - Describe, Inferences, Value Judgment }\end{array}$ & \\
\hline Intercultural Skills & \\
\hline$D U E$ - Describe, Understand and Encourage & \\
\hline
\end{tabular}




\section{CHAPTER III - RESEARCH DESIGN, DATA COLLECTION,}

\section{AND DATA ANALYSIS PROCEDURES}

This section will report the methods selected for this study including the research design of the study, the design of the survey questionnaire used to collect data, and data analysis procedures including qualitative and quantitative approaches.

A workshop survey questionnaire containing open-ended questions provided the data which were analyzed in this study. The workshop questionnaires (see appendix A) utilized a "recalled critical incident" to stimulate thought and then asked for short answers to a series of questions. The entire organizational population filled out the workshop questionnaire at the beginning of a required one-day diversity training. The researcher developed typologies, performed a thematic analysis based on the typologies, and utilized descriptive statistics to analyze the themes by demographic characteristics.

\section{Research Questions}

The data analysis was conducted in response to the following research questions:

1. What were the discriminatory situations identified by organizational members?

2. How did the organizational members manage discriminatory situations?

3. What were the individual's follow-up responses to the situations?

4. What did members report they could have said or done differently? 
The goal of this research was to collect data regarding the topic of discrimination and describe themes and issues which emerge from the data. The research questions and design of questionnaire match several criteria listed by Frankel and Wallen (193, p. 380) in relation to qualitative research such as a "preference for hypotheses that emerge as study develops, preference for definitions in context or as study progresses, preference for narrative description, and a preference for holistic description of complex phenomena." In this study, the questionnaire asks respondents to think of a critical incident and then answer questions about this incident. The answers are recorded in narrative form, and contain information about the context, feelings, perceptions, and behaviors. The researcher is not interested in validation or invalidation of a particular hypothesis or theory, but instead, wants to describe how people talk about and understand discrimination. Since the researcher considers the responses a text to be examined, this study uses a qualitative modified analytic method to analyze the data (Frankel and Wallen, 1993). This method was selected because it permits collecting information in greater depth and detail than would be possible if a quantitative approach were used to gather data. The questions ask subjects to describe an incident and to talk about their attitudes, feelings, behaviors and perceptions of events.

Workshop questionnaires were administered to all diversity workshop participants at the beginning of one-day diversity trainings. Employees received training during the winter of 1993 and the spring and summer of 1994. 


\section{Data Collection}

This study uses a descriptive approach to data collection. Descriptive research is used to gather information about "events, beliefs, attitudes, values, intentions, preferences, or behaviors" (Taylor \& Bogdam, 1984, p. 91) and utilizes the data gathering techniques of surveys, interviews and observations. In this study, a survey was conducted with a questionnaire as the tool used to collect information. The questionnaire is an appropriate choice in gathering data when individuals are the sole sources of the data and when knowledge is desired about their attitudes, perceptions and understandings (Taylor \& Bogdam, 1984).

\section{Population and Sample}

The population surveyed consists of all the recipients of phase II training in a large governmental organization in the state of Oregon. There were approximately 1200 employees in the organization studied. Employees were required to participate in the diversity training. The ideal circumstance is to gather information from every individual to whom the research applies (Taylor \& Bogdam, 1984). Since the workshop questionnaires were administered at the beginning of workshop sessions, it was anticipated that the workshop questionnaires would reflect the entire organization. However, workshop questionnaires were collected from 897 employees, $75 \%$ of the total number of employees. Of the 897 returned, $3 \%$ were blank and $5 \%$ stated that they could not think of an incident to report.

Three hundred questionnaires were selected from the 825 completed for use in the data analysis stage. The sample of 300 consisted of a random selection of 200 respondents who identified themselves as Anglo and an exhaustive sample of 100 respondents who identified themselves as members of underrepresented groups. 


\section{Questionnaire Development}

\section{$\underline{\text { Design }}$}

The design of the survey instrument is appropriate for this study. The questionnaire asks open-ended questions about a broad range of subject experiences. Questions address information about situations respondents considered discriminatory, respondent feelings, behaviors, attitudes, perceptions, levels of knowledge, perceptions of choice, feelings of self-efficacy, and skills. Some of these are asked directly and some can be inferred from the way respondents answer the questions and the information contained in the answers.

Examples of the possible relationship of questions to experiences include the following. The questions related to attitudes ask subjects how they feel and think. Questions about behavior ask subjects what they said and did. Questions related to knowledge and perception ask about the situation, the relationship between the respondent and people they report in the incidents and if they could have done anything differently. Questions addressing skills ask what they did and how they felt about what they did. The demographic information gathered includes age, race or ethnic identity, and gender.

\section{Question Construction}

Frey et al. list several criteria for appropriate, meaningful and non biased question construction. Questions should be straightforward, clearly stated and use language appropriate for the specified audience. Questions should address only one issue and avoid leading respondents to answer in certain ways. Questions should avoid the use of emotionally charged language. Indirect questions can be used to ask about areas that the respondent may not wish to reveal or respond to directly. 
The questionnaire developed for this study asks directly for the circumstances, the significant factors about the people, what they did in relation to the incident, and what they thought. It utilizes non directive open-ended questions asking for short answer responses. The format used in this study most resembles the tunnel format in which a "series of similarly organized questions" are asked and provide "researchers with a consistent series of responses to code" (Frey et al., p. 93)

\section{Order \& Wording}

The order of questions and wording of questions influences the responses (Patton, 1990). In this study, the first question (see Appendix A) asked the respondent to recall an actual scenario and then asked about specific details. This allowed the respondents to use specific details to a particular situation rather than a generalized response to abstract contexts.

In order to gather accurate data, questions must be appropriate for an audience intended. Cultural and educational settings must be considered and language chosen which is understandable and familiar. In addition, adult learning theory suggests that adults do not like to be talked down to and using jargon is one way of talking down to people (Arnold \& McClure, 1989). Hence, the wording of workshop questionnaires in this study reflect common language use rather than academic jargon. Examples of words used in questions include: "discriminatory, racist, sexist, ageist, relationship, situation, behavior, what did they say, what did you think, what did you feel." The wording was chosen with the hope that the questions would not be threatening or imposing and to invite genuine response.

\section{Confidentiality and Questionnaire Administration}

In order to encourage accuracy and detail in reporting, it is important that respondents feel that their confidentiality is protected. It is also helpful to make sure 
the respondents understand the significance of the survey and its impact. Thus, workshop questionnaires were administered as a prelude to workshop training by the trainers who were facilitating the workshops. The questionnaires were collected anonymously in the group setting.

\section{Critical Incident Framework}

The measure utilized in this study was participants' short answer responses to questions about a critical incident in relation to a discriminatory situation. J. Flanagan (1954) developed an exploratory qualitative research method called the critical incident technique. This is a procedure for gathering information about behaviors in particular situations (Flanagan, 1954). In 1965, Andersson \& Nilsson concluded "that information collected by this method (critical incident technique) is both reliable and valid. Although it was used in the psychology field in the development of job descriptions and qualifications, has been used irregularly since the 1950's and it is not generally included as a standard research method (Woolsey, 1986). Flanagan (p. 327) defines an incident as:

any observable human activity that is sufficiently complete in itself to permit inferences and predictions to be made about the person performing the act.

An incident that is "critical":

must occur in a situation where the purpose or intent of the act seems fairly clear to the observer and where its consequences are sufficiently definite to leave little doubt concerning its effects.

Techniques for gathering critical incidents include self-reports or observations by a designated person trained to observe and report critical incidents, usually in a work situation. As Flanagan suggests, while observed incidents may be preferable, a more efficient and practical approach may be to use recalled incident data (Flanagan, 1954). 
Typically, critical incidents are collected which describe the behaviors relevant to a particular job. The behaviors are categorized and yield the critical requirements for effective job performance. The number of critical incidents collected depends upon the complexity of the activities described. Simple activities may require 50 to 100 critical incidents while complex activities may require 2000 to 4000 (Flanagan, 1954; Woolsey, 1986). Generally, critical incidents are gathered until data repetition occurs and few new behaviors are described with the addition of new incidents (Flanagan; Woolsey).

Critical incidents are collected with a "general aim" in mind. "No planning and no evaluation of specific behaviors are possible without a general statement of objectives" (Flanagan, 1954, p. 336). In this study, the trainer's objectives were stated and the critical incidents designed to gather data pertinent to those objectives. Flanagan states,

The most useful statements of aims seem to center around some simple phrase or catchword which is sloganlike in character. Such words provide a maximum of communication with only a minimum of possible misinterpretation (p. 337).

In this study, the catchword utilized in the opening paragraph of the questionnaires is "Discriminatory". This word connotes situations and attitudes which might be addressed in a diversity training workshop.

Once data has been collected, the researcher must classify and make inferences about the data. Congruent with the analytic approach outlined earlier, an inductive approach is usually taken when classifying the data (Flanagan, Woolsey). "Formulation of categories is done inductively, by sorting incidents into clusters that seem to group together (Woolsey, 1986)." 
Flanagan notes that the "most simple and natural application" of this method is a "procedure for evaluating the typical performance" (p. 346). Flanagan cites Collins" (1954, in Flanagan) unpublished dissertation in which critical incidents were used to evaluate the effectiveness of a training program.

The types of incidents reported by mothers after a two-week training course were significantly different from those reported at the beginning of the program in a number of aspects relevant to the objectives of the program. The critical incidents appeared to provide a much more sensitive basis for revealing changes than other procedures used.

One strength of this method is that it is flexible (Woolsey, 1986) and can be adapted to a variety of contexts. In this study, self-reported, recalled critical incidents are used as a stimulus. Subjects are asked to define and assess an incident out of their own experience.

Woolsey (1986) points out another strength when she says:

Critical incident studies are particularly useful in the early stages of research because they generate both exploratory information and theory or model-building. As such, they belong to the discovery rather than the verification state of research.

One effective training method used by diversity trainers involves participants analyzing critical incidents (Pusch, 1979; Bramley, 1991). Participants analyze an interaction which involves using their knowledge and understanding of issues of diversity. Brislin \& Yoshida note that one benefit of intercultural training is an increase in "the ability to solve difficult critical incidents that demand a knowledge of culture and cultural differences, and the ability to analyze critical incidents in one's own life" (1994, p. 166). Although the questions in this study do not ask participants to solve a given critical incident, it does ask for participants to think of a situation which was discriminatory (a critical incident) and then asks for information regarding this incident. 
Descriptions of critical incidents should include pertinent information about the individuals, the activity, the location and conditions, and the specific behaviors or experiences (Woolsey, 1986). Duley (1975) outlines the components of a critical incident and suggests that it answer the following questions:

1. Which skill is the incident related to?

2. What was at issue?

3. What were the circumstances surrounding the event which are important to it?

4. Who were the people? (significant factors about them)

5. What other information would help make the circumstances more understandable?

6. What did you do or how did you behave (describe in detail) in attempting to use the skill in the above circumstance.

\section{Reliability and Validity}

According to Patton, "the validity and reliability of qualitative data depend to a great extent on the methodological skill, sensitivity, and integrity of the researcher" (1990, p. 199). One advantage in this study is the high response rate to the survey so that responses will reflect the entire organization. The results should be generalizable to the organization from which the questionnaires were collected.

The critical incident technique was reported to be valid by Andersson and Nilsson (1964) in representing the content domain. Other methods of assessing the same domain contributed no new data. Ninety-five percent of the categories arose by analyzing two thirds of the data, and "the subcategories were found to be stable" (p. 
251). Andersson and Nilsson concluded that "the method is both reliable and valid" (Woolsey, p. 251).

Validity is increased when the information is gathered in more depth. Since the questions are open-ended and ask for short answers, the data will be richer than closed-ended survey questions. This qualitative analysis may provide more depth of analysis than is available with quantitative methods only, thus enhancing the validity of this study.

\section{Pilot Study}

A questionnaire should be tested prior to the actual research in order to test questions for problems of misunderstanding, ambiguity and defensiveness (Miller, 1991). The questionnaire used in this research was developed by Lieberman (1993) and pretested. Lieberman (1993) asked undergraduate and graduate students at a Pacific Northwest State University to respond to the questionnaire. The responses were examined and analyzed by Lieberman and a group of graduate students. It was found that there was not enough space after question 3 for participants to respond in depth. The questionnaire was redesigned such that respondents had adequate space within which to answer.

The students also developed a preliminary typology (see Appendix B). Students coded behaviors into three behavioral categories: "Verbal Interactive," "Physical Interactive" and "Non-Interactive." The verbal interactive category included the subcategories: "Change Subject," "Asked Question," "Disagree," and "Explain Point of View." The "Physical Interactive" category included the subcategories: "Contact" and "No Contact." The "Non-Interactive" category included "Ignored" and "Leave Scene." 


\section{Data Analysis}

After collecting the data, the researcher employed a qualitative modified analytic method of analysis to identify themes and issues within the data. "The value of a content-analytic study rests on developing valid categories into which units can be classified" (Frey et. al, 1991, p. 215). The researcher utilized the open coding process to break down, examine, compare, conceptualize and categorize the data (Strauss \& Corbin, 1990). Then the researcher utilized axial coding to "put those data back together in new ways by making connections between a category and its subcategories" (Strauss \& Corbin, 1990, p. 97). Finally, the researcher developed a conditional matrix as a framework that summarizes and integrates the themes and issues identified (Strauss \& Corbin, 1990).

Initially, the entire data set of 825 completed questionnaires was utilized in the generation of initial typologies and categories. The categories generated in a pilot study conducted earlier were utilized in one typology. A sample of 25 questionnaires were then utilized to test the typologies to verify that the categories were complete and mutually exclusive. A sample of 300 was then selected for data analysis. The sample of 300 consisted of a random selection of 200 respondents who identified themselves as Anglo and an exhaustive sample of 100 respondents who identified themselves as members of underrepresented groups.

\section{Coding Process}

The researcher generated typologies by looking for categories, patterns and themes to explain the data. The researcher looked for "recurring regularities" in the data (Patton, p. 403). The development of typologies involved three phases. The first 
was discovery phase in which the researcher looked at the data in as many different ways as possible in the search for themes (Taylor \& Bogdam, 1984). The researcher used the modified analytic method which involves coding and analyzing in order to develop themes (Taylor \& Bogdam, 1984, p. 126). The followed suggestions made by Taylor \& Bogdam for addressing this phase were followed by the researcher, including: 1) Read and reread your data; 2) Keep track of themes, hunches, interpretations, and ideas; 3) Look for emerging themes; 4) Construct typologies; 5) Develop concepts and theoretical propositions; 6) Read the literature; and 7) Develop a story-line.

The second phase involves coding the data. Coding is "a systematic way of developing and refining interpretations of the data (Taylor \& Bogdam, 1984, p 136). The researcher looked for "patterns, categories, and themes." Taylor's and Bogdam's suggestions for coding include: 1) Develop coding categories; 2) Code all the data; 3) Sort the data into the coding categories; 4) See what data are left out; and 5) Refine your analysis.

The final coding phase is called "discounting the data" and involves interpreting the data within the context from which it was gathered. Taylor and Bogdam (1984) list several considerations: 1) Is the data solicited or unsolicited? 2) Was there an observer influence on the setting? 3) Who was there that might influence the data? 4) Is the data direct or indirect? 5) Who are the sources of data? and, 6) What are your own assumptions and presuppositions?

In developing valid categories, the researcher relied on substance or the content of the message as well as form or the way the message was said (Frey et. al). 
The researcher developed categories which are "mutually exclusive, equivalent, and exhaustive" (Frey et. al, p. 214)

The approach used to develop the typologies was inductive. The researcher used inductive analysis to find patterns, themes and categories which emerged out of the data (Patton, 1990).

The strategy of inductive designs is to allow the important analysis dimensions to emerge from patterns found in the cases under study without presupposing in advance what the important dimensions will be... Categories or dimensions of analysis emerge from open-ended observations as the evaluator comes to understand program patterns that exist in the empirical world under study (Patton, p. 44).

The researcher used analyst-constructed typologies to sort the data. In this approach, "the analyst assumed the task of constructing and making explicit patterns that appear to exist but remain unperceived by the people studied (Patton, p. 398). Taylor and Bogdam (1984) explain that qualitative researchers code and analyze their own data. In this study, the researcher looked for themes and issues in the data. Since the researcher then becomes part of the analytic process, the stance of the researcher must be discussed.

Patton (1990) suggests that a stance of neutrality in which the researcher lets the data speak rather than to prove a particular theory or arrive at a predicted conclusion. This is a difficult stance to obtain and thus, requires the researcher to adopt strategies for dealing with investigator bias and dispositions toward preconceived interpretations. The researcher examines her own biases, preconceptions and assumptions so that she may set them aside during the analysis. The researcher in this study has difficulty speaking assertively when confronted with discrimination and has felt communicatively inept. She has found knowledge and experience in communication to be helpful in expanding her choices and in increasing her 
confidence in using communication choices. These expectations will be bracketed so that the researcher may set them aside during the analysis of questionnaires. Many researchers have now concluded that researcher bias is not absent in a hypotheticaldeductive model and an advantage of qualitative methods is that the researcher orientation is explicit.

\section{Survey Research}

Surveys are used often in communication research as a straight-forward technique to gather information by asking people questions and then analyzing their answers. They are frequently used to study beliefs, attitudes and behaviors (Frey, Botan, Friedman, \& Kreps, 1991) Surveys have been used to ask about relationships between communication and other variables and are frequently used to evaluate the effectiveness of programs or products by asking about respondents feelings or experiences (Frey et al). Surveys are advantageous in that they take less respondent and researcher time than interviews; they can reach a larger audience with less investment; they enhance anonymity; answers are preserved as recorded by respondents; and, since the same format is used each time, they provide consistent results.

While a closed-ended questionnaire (Frey et al., 1991) is a common method of gathering data about knowledge, feelings, attitudes, etc. and it can be administered and analyzed quickly, the quality of data gathered is restricted to a limited range of replies to the questions asked. In this study, open-ended, short answer responses were gathered, so the data is richer than data collected via closed-ended questions. A questionnaire utilizing short answers does not provide the depth of information that 
interviews can provide, and there is less personal interaction in gathering information resulting in no clarification if needed and less chance to encourage full and honest answers.

Surveys generally rely on correlational designs as opposed to direct manipulation and measurement of variables (Frey et. al, 1991). Hence, the design of the instrument is important and complex. Factors of importance include who is questioned and the response rate, order and wording of questions, question construction and administration, nature of self-reports and confidentiality (Frey et al, 1991).

\section{Self Reports}

Survey methods rely on self reports. Because information about attitudes is psychological and not observable, and because inferences made from observations about attitudes can be deceptive, self-reports are effective for gathering information about attitudes (Frey et al, 1991). Self-reports may also include data about how a respondent perceives a situation, what the respondent knows and how the respondent feels. For example, feelings of competence, or self-efficacy have been found to help skills transfer from training to the workplace (Bramley, 1991) and this information is only known by the respondent.

There are several disadvantages of using self-reports. "Self-reports ... depend on people's being able and willing to provide complete and accurate information" (Frey et al, 1991, p. 97). People may not be willing to honestly report behavior they are ashamed or embarrassed by or behavior that does not conform to social norms. Frey et al. say that "people ... tend to report inaccurately incidents that are unpleasant or ego-threatening" (p. 192). Therefore, since the questionnaires ask for information 
about a discriminatory situation which indeed may have been unpleasant or egothreatening, a limitation of this study is that the respondents may not report accurately.

Self-reports also assume that people can remember information accurately, which may not be the case. Finally, there may be differences between perception and actual behavior. As Frey et al. point out, "many times, what people say they do is not what they actually do" (p. 97). Although the information in the questionnaire is gathered through self-reports and limited in that sense, the questions are designed in such a way as to make it more difficult for subjects to respond with what they think the trainer wanted to hear. Respondents are asked to think of a specific situation in hopes that answering questions about specific situations will result in information that more closely corresponds to actual behavior than a question asking for imagined behavior to an abstract situation. 


\section{CHAPTER IV - RESULTS OF ANALYSIS}

This section reports the development of typologies which emerged from an analysis of the data, and reports findings about relationships between variables and themes. Since this study utilized categorical variables, chi-square statistics were computed. However, chi-square results could not be reported because of the large number of cells with very low frequency expectations. A number of relationships between key variables were analyzed using cross-tabulations and are reported in crossbreak tables. Tables summarize descriptive statistics and relationships between key variables and emergent themes, and apparent findings address the research purpose.

\section{Demographic characteristics of sample}

The questionnaires collected from workshop participants provided information about the demographic characteristics of gender, race or ethnicity, and age (see Table II.).

TABLE II

\section{Demographic Characteristics}

\section{Gender} Ethnicity/Race

Age

\begin{tabular}{|l|l|l|l|l|l|l|l|}
\hline Women & $52.7 \%$ & & European-American & $67.0 \%$ & $20-29$ & $9.8 \%$ \\
\hline Men & $46.3 \%$ & & Hispanic & $12.3 \%$ & $30-39$ & $21.0 \%$ \\
\hline Unidentified & $1.0 \%$ & & Asian & $6.7 \%$ & $40-49$ & $41.7 \%$ \\
\hline & & & African-American & $5.7 \%$ & $50-59$ & $17.4 \%$ \\
\hline & & & Native-American or NA/White & $8.0 \%$ & $60-65$ & $2.7 \%$ \\
\hline & & & Unidentified & $.3 \%$ & & Unidentified & $7.3 \%$ \\
\hline
\end{tabular}


Eight hundred twenty five organizational members provided responses to the questionnaire. Three hundred of these responses were selected for analysis. Of these $300,52.5 \%$ were women, $46.3 \%$ were men and $1.0 \%$ didn't specify their gender. Two-thirds of the sample were European-American; the remaining $32 \%$ included Hispanic, Asian, African-American and Native Americans. $40 \%$ of the respondents were between the ages of 40 to $49 ; 21 \%$ between 30 and $39 ; 17 \%$ between 50 and 59 ; and almost $10 \%$ were between 20 and 29 .

The following results are reported in response to research questions one through four. The researcher developed typologies describing the responses reported by participants. The typologies are described in this section and summarized in tables.

\section{Development of Typologies}

In conjunction with the interpersonal communication and conflict skills summarized in Table I, four typologies were developed by the researcher in response to the four research questions. The following sections explain the development of the typologies and report relationships between key variables and themes.

\section{Research Question \#1:}

\section{What were the situations identified by organizational members as discriminatory?}

Based on data in response to research question \#1, a typology was developed that summarized the situations. Within this typology, major divisions addressing the relationship, setting, and process emerged. Categories within the relationship division of this typology were labeled work related, close relationship, and not close relationship. The category labeled work related included the following subcategories: 
1) no work relationship, 2) customer relationship, 3) employer or boss relationship,

4) business-related relationship, and 5) co-worker relationship (see Table III).

TABLE III

Typology - Research Question \#1

\begin{tabular}{|c|c|c|}
\hline \multicolumn{3}{|c|}{ SITUATIONS IDENTIFIED } \\
\hline RELATIONSHIP & SETTING & PROCESS \\
\hline Work related & Business & Position \\
\hline $\begin{array}{l}\text { no relationship } \\
\text { customer } \\
\text { employer or boss } \\
\text { business related } \\
\text { co-worker } \\
\end{array}$ & & $\begin{array}{l}\text { other/unknown } \\
\text { observing } \\
\text { about self/self } \\
\text { conversation } \\
\text { group }\end{array}$ \\
\hline Close & Public & Type of Interaction \\
\hline $\begin{array}{l}\text { no relationship } \\
\text { relative } \\
\text { friend/neighbor }\end{array}$ & & $\begin{array}{l}\text { other } \\
\text { discriminatory behavior } \\
\text { discriminatory comment } \\
\text { joke/story } \\
\end{array}$ \\
\hline Not close & Home or Friends & Type of Discrimination \\
\hline $\begin{array}{l}\text { no relationship } \\
\text { acquaintance } \\
\text { professional } \\
\text { customer service }\end{array}$ & & $\begin{array}{l}\text { racial/ethnic } \\
\text { gender } \\
\text { age } \\
\text { language use/ immigrant status } \\
\text { sexual harassment } \\
\text { religion } \\
\text { unknown/other } \\
\text { sexual orientation } \\
\text { capable/handicap } \\
\text { personal appearance } \\
\text { weight } \\
\text { marital status } \\
\end{array}$ \\
\hline & Other & \\
\hline
\end{tabular}

The second category of close relationship included the subcategories: 1) no relationship, 2) relative, and 3) friend/neighbor relationship. Initially, friend and neighbor were two categories and were collapsed as they seemed reasonably similar . 
The third category of not close relationship included the subcategories: 1) no relationship, 2) acquaintance, 3) professional, and 4) customer service. While professional and customer service seem similar to work related, the researcher noticed that participants identified situations in which they were not at work but still in a customer service situation or dealing with a professional.

In relation to the major division labeled setting, the researcher developed the categories of other, business setting, public setting, and home or friends. At home and with friends were initially separate categories but were condensed.

The typology describing the situation is summarized in Table IV.

TABLE IV

Situations

\begin{tabular}{|l|l|l|l|l|l|l|l|}
\multicolumn{2}{|c}{ Relationship } & \multicolumn{7}{c}{ Setting } & & & conversation & $35.3 \%$ \\
\hline Coworker & $24.3 \%$ & & Business & $40 \%$ & & & \\
\hline Relative & $15.3 \%$ & & Public & $20 \%$ & about self/self & $18.7 \%$ \\
\hline Friend/Neighbor & $14.0 \%$ & & Home/friend & $9.7 \%$ & & other/unknown & $19.7 \%$ \\
\hline Customer & $9.7 \%$ & & Other & $30 \%$ & & observing & $12.0 \%$ \\
\hline Boss & $9.0 \%$ & & & & & & $14.3 \%$ \\
\hline Professional & $6.7 \%$ & & & & & & \\
\hline Acquaintance & $6.0 \%$ & & & & & & \\
\hline Customer Service & $2.7 \%$ & & & & & & \\
\hline None & $12.3 \%$ & & & & & & \\
\hline
\end{tabular}

$\mathbf{N}=\mathbf{3 0 0}$

A third major division in this first typology was labeled process and included the categories titled position of respondent, type of interaction and type of 
discrimination. Within the position of respondent category were the subcategories: 1) observing, 2) about self or by self, 3) in conversation, 4) in a group, and

5) other/unknown. Within the category labeled type of interaction were the subcategories: 1) discriminatory behavior, 2) discriminatory comment, and 3) joke/story. Originally, joke and story were separate subcategories but were condensed due to similarity of content in the data. $69.3 \%$ of the types of interaction were "discriminatory comments," $20.7 \%$ were "discriminatory behaviors," $7.3 \%$ were "joke or story telling" and 3.9\% were "other" (3.9\%). (See Table V.)

\section{TABLE V}

\section{Description of Incident}

Type of Interaction

Type of Discrimination

\begin{tabular}{|l|l|l|l|l|}
\hline discriminatory comment & $69.3 \%$ & & race or ethnic & $45.0 \%$ \\
\hline discriminatory behavior & $20.7 \%$ & & gender & $18.3 \%$ \\
\hline joke or story telling & $7.3 \%$ & & age & $7.3 \%$ \\
\hline other & $3.9 \%$ & & language use/immigrant & $4.7 \%$ \\
\hline & & & sexual harassment & $4.3 \%$ \\
\hline & & & religion & $2.7 \%$ \\
\hline & & & unknown/other & $9.0 \%$ \\
\hline & & & sexual orientation & $2.0 \%$ \\
\hline & & & capable/handicap & $2.0 \%$ \\
\hline & & & personal appearance & $1.7 \%$ \\
\hline & & & weight & \\
\hline & & & marital status & $1.7 \%$ \\
\hline & & & & $1.3 \%$ \\
\hline
\end{tabular}

$\mathbf{N}=\mathbf{3 0 0}$ 
$45 \%$ of the types of discrimination were described as "race or ethnic," $18.3 \%$ as "gender related," $7.3 \%$ as "age related," 4.7\% as "regarding immigrant status or lack of facility with English language," $4.3 \%$ as "sexual harassment related," and $9 \%$ as "other." One to two percent of the respondents reported discrimination related to "sexual orientation," "a handicap," "personal appearance," "weight," or "marital status" (see Table V).

\section{Type of Discrimination by Setting}

A cross-tabulation of the type of discrimination by setting showed that racial/ethnic and gender related discrimination occurred most often no matter what the setting. Interestingly, in the home or friends setting, other types of discrimination based on factors such as religion, marital status, personal appearance, language use or immigrant status, capability, sexual harassment, sexual orientation and weight occurred infrequently or never. Seventy seven percent of the sexual harassment incidents reported occurred in a business setting (See Table VI).

Table VI

\section{Type of Discrimination by Setting}

\begin{tabular}{|l|l|l|l|l|}
\hline \multicolumn{1}{|c|}{ Business } & & \multicolumn{1}{|c|}{ Public } & & \multicolumn{1}{c|}{ Home } \\
\hline Race (33\%) & & Race (62\%) & & Race (62\%) \\
\hline Gender (21\%) & & Gender (10\%) & & Gender (21\%) \\
\hline Age (11\%) & & Unk/other (10\%) & & Unk/other (7\%) \\
\hline Sex Harrasm (8\%) & & & & \\
\hline Unk/other (8\%) & & & & \\
\hline
\end{tabular}




\section{Research Question \#2:}

How do the organizational members manage discriminatory situations?

A second typology was developed in relation to research question $\# 2$. In answering this question, the researcher utilized a typology originating from a pilot study describing how members managed discriminatory situations. The typology included the categories of verbal, nonverbal, and action. While several categories yielded very few responses, the researcher felt it important to include them as data about the full range of possible responses to discrimination.

The typology contained the major division of managed situations verbally, managed situations nonverbally, and managed situations through action.

TABLE VII

Typology - Research Question \#2

RESPONSES - MANAGING DISCRIMINATORY SITUATIONS

\begin{tabular}{|l|l|l|}
\hline \multicolumn{1}{|c|}{$V E R B A L$} & \multicolumn{1}{|c|}{ NONVERBAL } & \multicolumn{1}{c|}{ ACTION } \\
\hline none/other & none & none \\
explained & smiled & complied \\
embarrassed other & watched & walked away \\
continued behavior \\
laughed & didn't laugh & informed superior \\
advised - discrimination laws & bit tongue, silence & moved to face \\
state own ethnicity & ignored & \\
stated feelings/thoughts & listened & \\
asked not to say & polite, positive & \\
come back remark & friendly & \\
"nothing" & spoke strongly \\
defended & let someone else speak & \\
apologized & cried & \\
cursed & shook head & \\
diverted conversation & got angry & \\
asked questions & & \\
agreed & & \\
\hline
\end{tabular}


Within the major division of managed situations verbally were the subcategories explained, embarrassed the other, laughed, advised regarding discrimination laws, stated own ethnicity, stated feelings or thoughts, asked the other not to say that, made a come back remark, "nothing", defended or stood up to the person, apologized, cursed at them, diverted the conversation, asked questions, agreed and none.

\section{TABLE VIII}

\section{Management of Discriminatory Situations}

Verbal

Nonverbal

Action

\begin{tabular}{|c|c|c|c|c|c|}
\hline "nothing" & $20.7 \%$ & ignored & $8.3 \%$ & showed thr actn & $9.0 \%$ \\
\hline no or other & $31.3 \%$ & listened & $2.7 \%$ & complied & $2.0 \%$ \\
\hline stated thots/feel & $18.3 \%$ & shook head & $1.3 \%$ & informed supr & $1.7 \%$ \\
\hline explained & $7.0 \%$ & other/none & $87.6 \%$ & continued beh & $1.0 \%$ \\
\hline advised - disc law & $5.0 \%$ & & & none & $86.3 \%$ \\
\hline diverted convers & $3.3 \%$ & & & & \\
\hline asked questions & $3.0 \%$ & & & & \\
\hline defended/std up & $2.3 \%$ & & & & \\
\hline laughed & $2.0 \%$ & & & & \\
\hline asked not to say & $2.0 \%$ & & & & \\
\hline
\end{tabular}

$\mathbf{N}=\mathbf{3 0 0}$

Within the major division of managed situations nonverbally were the subcategories of smiled, watched, didn't laugh, laughed, bit tongue or silence, ignored, listened, polite and positive, friendly, spoke strongly, let someone else handle it, cried, shook head, got angry, and none. 
Within the major division of managed situations through action were the subcategories of complied, showed through action or walked away, continued behavior, informed superior, moved to face, hit the person, or no action.

The typology describing how participants' managed discriminatory situations is summarized in Table VIII. In relation to question 1c: "What did you say or do at the time? the verbal responses were coded as stated their thoughts or feelings (18.3\%), explained (7\%), and advised regarding discrimination laws (5\%).

Additional responses included diverting the conversation, asked questions, laughed, asked the other not to say that, and defended or stood up to the person. Interestingly, $31.3 \%$ were categorized as not responding to the question or the response fell into other and $20.7 \%$ reported the specific overall response: nothing.

Nonverbal responses were categorized as ignored, listened, and shook head. However, the majority of responses were coded as other/none (87.6\%). Responses indicating that the person took action of some sort were coded as showed through action, complied, informed superior, continued behavior. Again, the majority of responses indicated no action (86.3\%).

\section{Type of Discrimination by Type of Interaction}

Jokes and stories were most often about race/ethnicity, discriminatory comments were most often about race/ethnicity, gender, age, or other; and discriminatory behaviors were in relation to race/ethnicity, gender and other.

\section{Management of Situation by Position of Participant}

The way participants managed situations depended upon the position of the respondent in relation to other people present in the situation. When the participant reported a group situation, the management strategies chosen were "nothing," take no 
action, or no response reported. When the participant was engaged in conversation, a wider range of management strategies were chosen. including stating their feelings, advised regarding discrimination, explained, diverted conversation and asked questions. A nonverbal option chosen was to ignore the discrimination. Participants showed through action twice as often when in the self category as any other position. When participants reported the position as observing, the most common response was "nothing."

\section{Research Question \#3:}

\section{What were the individual's later responses to the situations?}

This third typology was developed in response to research question \#3 based on responses to question 2a: "If you thought of the situation later, what did you think?" and $2 \mathrm{~b}$ : "What did you feel?"

Within the major division of later thinking responses are subcategories which range from philosophize and make a social comment to not thinking about it at all (See Table IX.) While most of the category titles are fairly descriptive of types of comments within each of the categories, some subcategory titles require explanation. The following highlights five of the subcategories together with examples of typical respondent comments for the category. 
TABLE IX

\section{Typology - Research Question \#3}

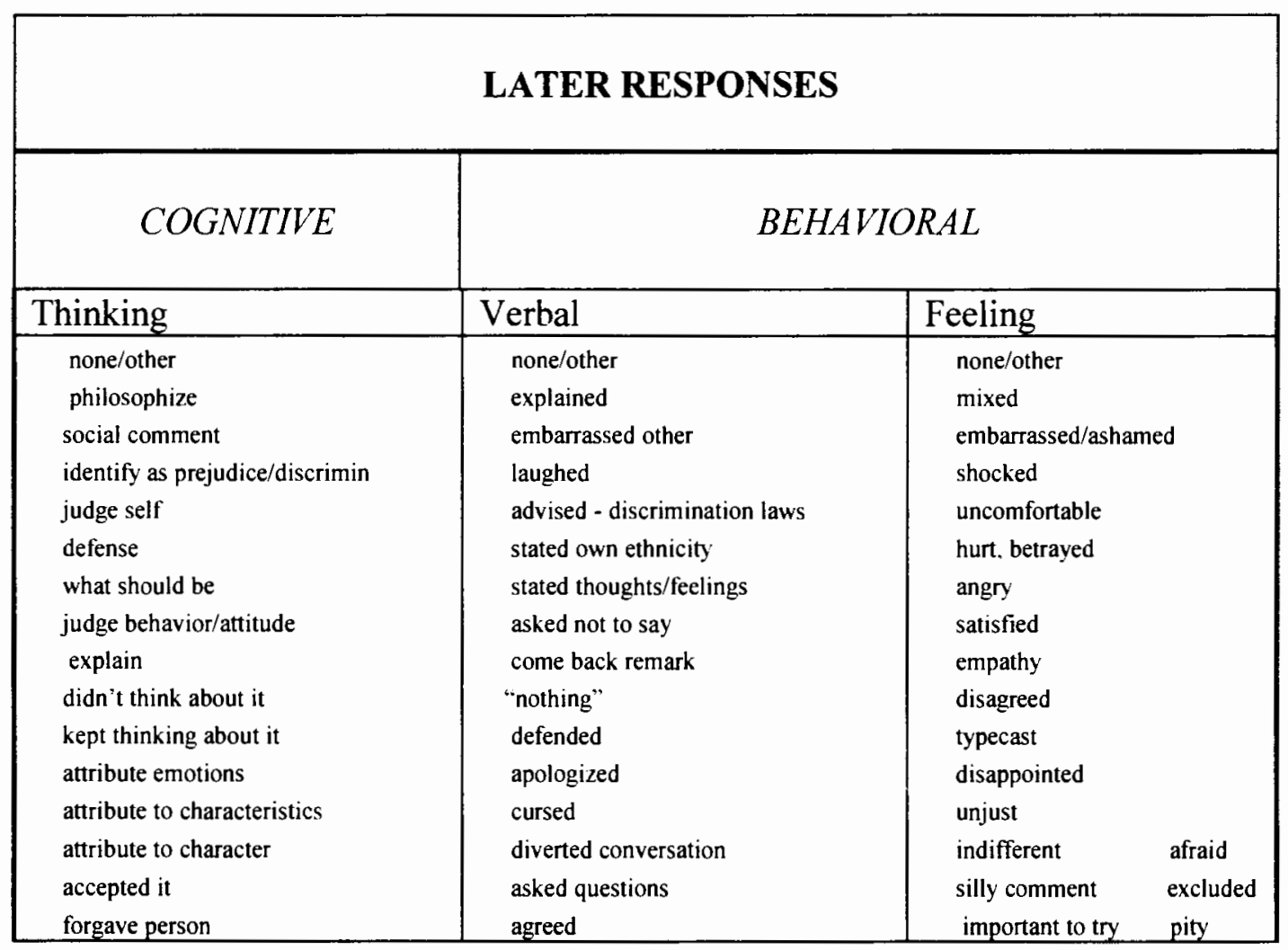

Philosophize: Participants reflected upon the situation and the behavior

"He has a lot to learn about other people. How would he feel if he found out that joke and bad remark were said about him" \#17,6 (\#17,6 = questionnaire number)

"I thought that this person had very little understanding of the role played by Mexicans in our valley and country." \#25, 8

"Sometimes you can't change people." \#61, 12

"I wondered how I would be acting if I were placed in the same situation." \#350,18 
Social Comment: Participants made comments that seemed to imply social concerns

"I thought I hope he doesn't have kids!" \#564, 38

"I felt it continued erroneous and prejudicial ideas of what a certain group's characteristics" \#9,41

"I thought people need more education." \#88,45

"People need to treat others like a human being. Need to work very close with other ethnic." \#134, 50

Judge Self: Participants made a comment about their own behavior in the situation

"I wasn't happy with myself and with the situation and that people are blatantly that way... mad at myself." \#60, 11

"Like maybe I could have said something to convince him that his views were wrong or incorrect." \#380, 21

"I was equally as bad. I reversed the situation to be directed at him." \#561, 36

"This conversation may have offended listeners. We should "cool it". \#471, 43

"I thought he was stupid and immature and I thought the same about myself." \#561, 36

Attribute Characteristics: Participants attributed the behavior to characteristics of the other person such as not thinking, not having respect, engaging in crude

description

"Not my fault - its the other person who feels dislike of the ethnicity /nationality" \#346, 16

"How she fell into a very crude description of a woman's appearance." \#254, 58

"No respect for others." \#305, 62 
"The guy wasn't thinking." \#46, 46

"Pity that he's tied to such a narrow vision." \#107, 127

Attribute Character: Participants used a label to describe the other person and attributed the behavior to the person's character

"He is a bum!" \#319, 14

"That he was a royal Pig and he would not make a commission of me." \#355, 20

"He was a loser." \#454, 26

"That the employer was very simple minded." \#298, 60

"What a sleaze bag he was." \#77, 117

"That my boss was a jerk." \#124, 130

Within the major division of later feeling responses are subcategories which range from embarrassed or ashamed to indifferent as well as a combination of feelings. (See Table X.) 
TABLE X

Thoughts and Feelings About the Situation

Thinking Feeling

\begin{tabular}{|c|c|c|c|}
\hline judge behavior/attitude & $17.0 \%$ & none & $23.0 \%$ \\
\hline none & $16.3 \%$ & angry & $22.0 \%$ \\
\hline attribute to character & $14.0 \%$ & uncomfortable & $11.3 \%$ \\
\hline philosophize/social comment & $13.4 \%$ & hurt & $8.7 \%$ \\
\hline explain & $11.7 \%$ & embarrassed & $6.3 \%$ \\
\hline identify as prejudice/discrim & $8.3 \%$ & sad & $5.0 \%$ \\
\hline judge self & $6.3 \%$ & & \\
\hline didn't think about it & $4.0 \%$ & & \\
\hline kept thinking about it & $2.7 \%$ & & \\
\hline what should be & $2.3 \%$ & & \\
\hline accepted & $2.0 \%$ & & \\
\hline attributed characteristic & $2.0 \%$ & & \\
\hline
\end{tabular}

$\mathbf{N}=\mathbf{3 0 0}$

\section{Feeling Later Responses by Ethnicity and Gender}

Cross-tabulations suggested that, while the emotions of anger,

uncomfortableness, hurt or betrayal seemed evenly distributed across race-ethnicity, there was a difference in the occurrence of the emotion of shame/embarrassment.

While $8 \%$ of Europeans-Americans expressed this emotion, only $1 \%$ of underrepresented groups expressed embarrassment/shame. $9 \%$ of women expressed shame/embarrassment compared to $4 \%$ of the men. $26 \%$ of the women expressed 
anger compared to $19 \%$ of the men. $5 \%$ of the men expressed indifference while there were no women who expressed this response.

Thinking Later Responses by Gender

Cross-tabulations suggested that $20 \%$ of women judged the behavior compared to $13 \%$ of the men. $1 \%$ of the women said they didn't think about it compared to $7 \%$ of the men. $16 \%$ of women attributed to character compared to $11 \%$ of the men. There were no women who responded by accepting it compared to $4 \%$ of the men.

\section{Research Question 4:}

What did members report they could have said or done differently?

A fourth and final typology was developed that addresses RQ4. In response to question 3: "What could you have said or done differently in that situation?" a typology of responses that were categorized as verbal, nonverbal, physical, and cognitive responses. The cognitive responses are titled thoughts. The specific responses are summarized in Table XI.

TABLE XI

Typology - Research Question \#4

\begin{tabular}{|c|c|c|c|}
\hline \multicolumn{4}{|c|}{ MEMBERS COULD HAVE DONE DIFFERENTLY } \\
\hline Verbal & Nonverbal & Physical & Thoughts \\
\hline $\begin{array}{l}\text { state feelings/beliefs } \\
\text { pointed out discrimination } \\
\text { explain } \\
\text { nothing or no response }\end{array}$ & $\begin{array}{l}\text { ignore } \\
\text { manage emotions } \\
\text { none }\end{array}$ & $\begin{array}{l}\text { gone to superior } \\
\text { walked away } \\
\text { wrote letter } \\
\text { none }\end{array}$ & $\begin{array}{l}\text { "nothing } \\
\text { not sure } \\
\text { continued to work on } \\
\text { none }\end{array}$ \\
\hline
\end{tabular}


The typology included the major divisions of verbal done differently, nonverbal done differently, and physically done differently, and thoughts done differently. Within the major division of verbal done differently were the subcategories: 1) stated thoughts or feelings, 2) pointed out discrimination, 3) explained, 4) "nothing" and 5) no response.

\section{TABLE XII}

\section{Said or Done Differently}

Verbal

Nonverbal

\begin{tabular}{|l|l|l|l|l|}
\hline State feelings/beliefs & $9.0 \%$ & & ignore & $4.0 \%$ \\
\hline pointed out discrimination & $4.7 \%$ & & manage emotions & $3.7 \%$ \\
\hline explain & $3.0 \%$ & & none & $90.7 \%$ \\
\hline nothing or no response & $75.0 \%$ & & & \\
\hline
\end{tabular}

Physical

Thoughts

\begin{tabular}{|c|c|c|c|}
\hline gone to superior & $3.3 \%$ & "nothing" & $17.0 \%$ \\
\hline walked away & $2.3 \%$ & not sure & $12.0 \%$ \\
\hline wrote letter & $2.3 \%$ & continued to work on & $8.3 \%$ \\
\hline none & $89.0 \%$ & none & $54.0 \%$ \\
\hline
\end{tabular}

$\mathrm{N}=300$

Within the nonverbal done differently major division were the subcategories: 1) ignore, 2) manage emotions and 3) none. Within the physically done differently major division were the subcategories: 1) gone to superior, 2) walked away,

3) wrote letter, and 4) none. Within the thoughts done differently major division were the subcategories: 1) "nothing," 2) not sure, 3) continued to work, and 
4) none. Interestingly, the majority of responses in all four categories was either "nothing" or no response to the question (see Table XII).

Physically Done Differently by Ethnicity

Cross-tabulations suggest that there may be a cultural difference in physical strategies chosen. Seven percent of all other groups chose writing as a strategy in addressing discrimination. Hispanic, Asian and Native Americans wrote letters while no European and African-Americans chose this approach.

Thoughts About What to Do Differently by Gender

Cross-tabulations suggest that twice as many women as men "continued to worry". (women: $11 \%$, men: $5 \%$ ). Additionally, in reply to what they could do differently, men reported "nothing" twice as often as women (men: 24\%, women: $11 \%)$. 


\section{CHAPTER V - DISCUSSION}

The following discussion of the data analysis in this study provides an overview of organizational members' understandings of discrimination. It describes participants' understandings of what constitutes a "discriminatory incident," the context and relationships most often involved in discriminatory incidents, and participants' responses, thoughts and feelings in relation to these incidents. One section also comments upon a gap in the literature and on areas in which the researcher had expectations that the findings did not support. One goal of this survey was to provide information that can be utilized by organizations and by trainers in designing future diversity programs. Hence, later sections discuss implications for organizations and diversity training based on the demographic variables of gender, age and ethnicity and the emergent themes of interest. Final sections address the limitations of this study and implications for future study.

\section{Description of Contexts}

\section{Ongoing Relationships}

Participants most often recalled discriminatory incidents involving ongoing relationships. When asked to recall incidents of discrimination, participants recalled an incident involving a friend, neighbor or relative $29.3 \%$ of the time; a co-worker $24.3 \%$ of the time, or a boss $9 \%$ of the time. Thus, when asked to recall a critical discriminatory incident, $63 \%$ or two-thirds of the discriminatory incidents remembered involved a person of some significance in the participant's life. Recalling someone reasonably well-known to the participant indicates an investment in a long-term rather than a passing or stranger relationship. Another $26 \%$ or one-quarter of the time, participants recalled an incident in which there was some relationship such as 
customer, professional, acquaintance, or customer service situation. In only $12 \%$ of the time was there no relationship reported between the participant and the other people mentioned in the incident.

Thus, when organizational members in this study were asked to recall discriminatory incidents, they tended to describe incidents with people they know and interact with often or occasionally. The communication choices most people made were in the context of an ongoing relationship. In talking about conflict in ongoing relationships, Mayers (1989) stresses the need to address a breach as soon as it is recognized. If left unaddressed, unexpressed feelings and resentments may build. Perceptions and assumptions about the incident are not clarified or discussed, contributing to future interactions built upon expectations about interaction derived from prior experiences. Ongoing breaches are noticed and interpreted based upon prior experiences. What might have initially been a manageable incident may escalate into a significant barrier or wall (Mayers, 1989).

\section{Discrimination Reported Less Often in Home or with Friends}

Participants reported the discriminatory incident to occur often in a business setting (40\%) and often in an unspecified setting (30\%). Participants reported the incident to occur less often in a public setting (20\%) and occasionally at home or with friends $(10 \%)$. There could be several reasons for discrimination reported less often at home or with friends. It may be that the public embarrassment, humiliation, or restrictiveness of the business or public settings caused the incident to be more memorable than those that occurred at home or with friends. Also, since the participants were being asked to respond to the questions in a business setting, the incidents recalled may reflect the business context. It also may be that the values of 
friends and family members may be closer aligned with the participant's values, resulting in fewer observations of discriminatory behavior.

\section{Types of Discrimination}

Similar to Lalonde and Cameron's findings (1994), gender, race/ethnicity and age were the most often cited types of discrimination in this study. In business settings, gender and race/ethnicity were cited in $53 \%$ of the incidents, in public settings $72 \%$ of the time, and in home settings $83 \%$ of the time.

\section{Responsibility}

In describing the setting, participants often reported the type of communication interaction involved. The most often reported position of the participant in relation to other people involved in the incident was in a conversational setting ( $35 \%$ of the time). Thus, one third of the time, there was a one-to-one relationship between the two people. Twenty percent of the time the position of the participant was not mentioned. Nineteen percent of the time the participant either recognized him or herself as the person acting in a discriminatory manner, or identified the discrimination to be directed at him or herself. Thus, more than half of the time (55\%), the participant was involved in the interaction, possibly increasing the perceived responsibility for choosing a communication response. Fourteen percent of the time the participant was part of a group and $12 \%$ of the time the participant was an observer. Therefore, more than a quarter of the time (26\%) the participant was more removed from the interaction as part of a group or an observer, thus possibly decreasing responsibility for directly confronting the discriminatory incident. It may 
be that a participant would more often recall an incident as significant if it was one in which they felt more direct responsibility for addressing the perceived discrimination.

Cross-tabulations suggest that there were a few differences in responses chosen by participants in relation to the composition of interaction. Fifteen percent of the conversation or self participants explained while $2 \%$ of the group or observing participants explained; $34 \%$ of the conversation or self participants stated feelings or thoughts while $28 \%$ of the group or observing participants stated feelings or thoughts; and only $23 \%$ of the conversation or self participants said nothing while $63 \%$ of the group or observing participants said nothing. While more aggressive behaviors such as embarrassed the other or cursed happened infrequently overall, when they did occur they were all in the conversation or self situations.

It may be that the more direct responsibility a participant perceived such as in a one-to-one context, the more likely a participant would speak up directly. It is also possible that group norms and social norms limit any type of confrontive response. However, some assertive behaviors occurred in all settings such as advising about discrimination laws, asked not to say, and defending. And some responses seemed to occur no matter what the composition such as making a comeback remark, stated feelings and thoughts, and advising about discrimination laws. In this study, advising people about discrimination laws was part of the job responsibilities of many organizational members. Thus, established protocols for informing clients may have supported this particular response. 


\section{Interpersonal Skills}

\section{Relative Ability to Identify and Analyze Discriminatory Situations}

Participants seemed able to identify a discriminatory incident but had difficulty analyzing the situation to choose a communication strategy. Lalonde and Cameron (1994) observe that the literature on research in responses to discrimination suggest that there are two stages of responding to discrimination:
a) the acknowledgment that discrimination has indeed occurred, and
b) an analysis of the situation in order to determine which strategy of action, if any, to adopt.

In this study, participants were asked to identify a discriminatory incident. Of the 897 surveys returned, $31(3 \%)$ were blank and $46(5 \%)$ stated that they could not think of an incident to report. Hence, $92 \%$ of the people who responded could recall and identify a discriminatory incident, thus acknowledging to themselves and to the person collecting the data that discrimination had occurred. When participants acknowledged a discriminatory incident, $77 \%$ of the time discrimination was perceived as a verbal action such as a comment, joke or story. Another $21 \%$ of the time discrimination was perceived as a behavior. Thus, participants were able to identify some components of the discriminatory situation. In relation to Lalonde and Cameron's first stage, participants were successful in identifying at least one discriminatory incident, at least to some degree.

However, participants were less effective at Lalonde and Cameron's second stage, analyzing the situation in order to determine which strategy of action to adopt. A later section of this thesis discusses the limited choices initially made by participants. The majority of participants, when asked what they could have said or 
done differently, were not sure, said "nothing" or gave no response to the question. Forty one percent came up with some alternative, meaning that $59 \%$ could think of no other options to the situation than the one implemented.

In recalling a critical incident, participants identified one incident out of many possible incidents. The feelings reported by participants in relation to their incidents were largely negative. For some reason these incidents were memorable. Since there is a tendency to recall the negative over the positive, it may be that there is an embedded bias towards collecting incidents associated with negative feelings when using "recalled critical incidents".

It may be that participants can identify discrimination because of the gut or feeling level experience that accompanies the incident. However, the type of analysis necessary to choose a strategy for action requires bridging the gap between feeling knowledge that something happened and an analytic knowledge of assessing situations and choosing actions.

\section{Conflict or Discrimination as Opportunity}

As mentioned above, participants most often recalled the negative aspects of the interactions and reported negative feelings in response to conflict and discrimination. Situations were not seen as opportunities for building relationships or problem solving. Organizational, family or friendship norms around conflict may make addressing breaches especially difficult, however. Mayer (1989) tells us that a common reaction to conflict is to ignore or overlook the breach, or smooth things over. According to Mayer:

Conflict has a bad name. People associate it with destructiveness-with antagonism, uncomfortable relationships, loss of jobs, broken families, violence, and war. This understandable human reaction leads to the avoidance of 
confrontation, which paradoxically, is a primary reason conflicts grow to destructive proportions. This reaction also obscures the necessity of managing. rather than avoiding, conflict to the success of any organization. The full success of commercial organizations, government groups, families, and friendships depends upon the willingness to address differences and the know-how to do so effectively.

Wile (1988) suggests that relationships can be built on a problem.

Blending your problems into your relationship isn't just learning to live with them. Its also turning them into advantage. Problems have two particularly powerful advantages. They can be used as: 1) Pathways to intimacy, and 2) clues to important issues in the relationship.

Since conflict and discrimination are perceived as a negative occurrences and to be avoided in the dominant U.S. culture, rather than as "opportunity," not acknowledging the negative incident is a common remedy. Confronting a breach may involve violating cultural, social, organizational, and familial norms. "Bucking" a norm to confront a breach may be especially difficult because of the long-term consequences of nonconformity to the accepted patterns.

Often a discriminatory incident would involve a member of a dominant group and a member of a nondominant co-culture. In this case, there may be political consequences to the act of confronting a breach. It may take a great deal of confidence in one's skill and/or confidence in one's political position to confront a breach. Access to information about rules and legislation in relation to discrimination and confidence in the organization's commitment to them may be factors in one's choices about confronting discrimination.

The perceptions, analysis of the situation, and consequences involved in confronting discrimination may be different depending upon the type of relationship. If the incidents were most often with strangers, people might have found it either a) easier, or b) more difficult to confront a discriminatory incident. It may be easier to 
confront discrimination when the participant does not know the person and does not expect further interaction. There may be less worry about consequences to the future relationship and to the organizational political consequences, depending upon the situation, resulting in fewer barriers to confronting a discriminatory incident.

On the other hand, a person may find it more difficult to confront discrimination with a stranger. A stranger's response to the interaction may be unpredictable, and the uncertainty about a stranger's possible reactions may result in decreased likelihood of confronting discrimination. If there is not an ongoing relationship, the participant may not feel it worth the time and energy to invest in confronting the discriminatory incident, or may feel that it would take more time to adequately address the issue than the interaction warrants, or that nothing positive would come from it anyway.

However, most of the incidents reported in this study were within the context of a relationship of some kind. The social need for inclusion, for belonging to a personal relationship and being part of ongoing group is one need people meet through communication (Adler \& Rodman, 1991). Violating social norms by confronting a discrimination incident may be perceived as threatening to relationships which meet social needs for inclusion.

\section{Managed the Situation - Assumptions and Responses}

Participants described many perceptions, attributions, assumptions, and judgments, but very few did any question-asking or listening to check the accuracy of their perceptions. Participants need skills in responding assertively, and in developing 
expertise in relationship-building responses. The researcher devised a typology summarizing the ways that participants' managed the situations (see Table XIII).

\section{Assertive Responses Needed}

In relation to the literature review about the possible responses to conflict situations, the researcher titled the categories assertive responses; relationship building responses; indirect, appeasing or placating responses; defensive or aggressive responses; and a lack of response. In answer to the question "What did you say or do at the time?" the most often reported response (73\%) was actually no verbal, physical or nonverbal response or the verbal response "nothing." The researcher considers this to be one of the most significant findings of the study and will comment in a separate section.

Mayers tells us that assertiveness is an effective response to confronting conflictual situations and that avoiding and aggressive responses contribute to the building of walls in relationships. When participants did report a response to the question "What did you say or do at the time?" they most often responded in an assertive manner $12.3 \%$ of the time. Assertive responses were categorizes as stating their thoughts and feelings, stating their own ethnicity, advising of discrimination laws, asking the other not to say what they said, speaking strongly, showing through action or informing a superior. Only 3.3\% of the participants took a more aggressive or defensive posture and cursed at the discriminator, came to the defense of someone, embarrassed the discriminator, made a "come-back" remark, got angry with the discriminator, physically moved to face the discriminator, or hit the discriminator. 
TABLE XIII

Managed Situations

\begin{tabular}{|c|c|c|c|c|}
\hline $\begin{array}{l}\text { Assertive } \\
\text { Response } \\
12.3 \% \text { Overall }\end{array}$ & $\begin{array}{l}\text { Relationship } \\
\text { Building Response } \\
4.3 \% \text { Overall }\end{array}$ & $\begin{array}{l}\text { Lack of } \\
\text { Response } \\
73.3 \% \text { Overall }\end{array}$ & $\begin{array}{l}\text { Indirect, Appeasing or } \\
\text { Placating Responses } \\
6.6 \% \text { Overall }\end{array}$ & $\begin{array}{l}\text { Defensive/Aggressive } \\
\text { Response } \\
3.3 \% \text { Overall }\end{array}$ \\
\hline \multicolumn{5}{|l|}{ VERBAL } \\
\hline $26 \%$ & $10 \%$ & $49 \%$ & $6 \%$ & $9 \%$ \\
\hline $\begin{array}{l}\text { asked not to say } \\
2 \%\end{array}$ & $\begin{array}{l}\text { asked questions } \\
3 \%\end{array}$ & $\begin{array}{l}\text { "nothing" } \\
20.7 \%\end{array}$ & $\begin{array}{l}\text { diverted } \\
\text { conversation } \\
3.3 \% \\
\end{array}$ & $\begin{array}{l}\text { cursed } \\
0.7 \%\end{array}$ \\
\hline $\begin{array}{l}\text { stated thoughts/feeling } \\
18.3 \%\end{array}$ & $\begin{array}{l}\text { apologized } \\
0.3 \% \\
\end{array}$ & $\begin{array}{l}\text { no/other } \\
28 \%\end{array}$ & $\begin{array}{l}\text { agreed } \\
0.7 \% \\
\end{array}$ & $\begin{array}{l}\text { defended } \\
2.3 \%\end{array}$ \\
\hline $\begin{array}{l}\text { stated own ethnicity } \\
1 \%\end{array}$ & $\begin{array}{l}\text { explained } \\
7 \% \\
\end{array}$ & & $\begin{array}{l}\text { laughed } \\
2 \% \\
\end{array}$ & $\begin{array}{l}\text { embarrassed other } \\
0.3 \%\end{array}$ \\
\hline $\begin{array}{l}\text { advised - discr laws } \\
5 \%\end{array}$ & & & & $\begin{array}{l}\text { come back remark } \\
5 \%\end{array}$ \\
\hline \multicolumn{5}{|l|}{ NONVERBAL } \\
\hline $0.5 \%$ & $3 \%$ & $85 \%$ & $11 \%$ & $0.5 \%$ \\
\hline \multirow[t]{5}{*}{$\begin{array}{l}\text { spoke strongly } \\
0.3 \%\end{array}$} & $\begin{array}{l}\text { listened } \\
3 \% \\
\end{array}$ & $\begin{array}{l}\text { none } \\
84 \% \\
\end{array}$ & $\begin{array}{l}\text { smiled } \\
0.7 \% \\
\end{array}$ & $\begin{array}{l}\text { got angry } \\
0.3 \%\end{array}$ \\
\hline & $\begin{array}{l}\text { friendly } \\
0.3 \% \\
\end{array}$ & $\begin{array}{l}\text { watched } \\
0.3 \% \\
\end{array}$ & $\begin{array}{l}\text { bit tongue, silence } \\
0.3 \%\end{array}$ & \\
\hline & & $\begin{array}{l}\text { let someone else } \\
\text { respond } \\
0.7 \%\end{array}$ & $\begin{array}{l}\text { ignored } \\
8 \%\end{array}$ & \\
\hline & & & $\begin{array}{l}\text { cried } \\
0.7 \%\end{array}$ & \\
\hline & & & $\begin{array}{l}\text { shook head } \\
1 \%\end{array}$ & \\
\hline \multicolumn{5}{|l|}{ ACTION } \\
\hline $10.5 \%$ & $0 \%$ & $86 \%$ & $3 \%$ & $0.5 \%$ \\
\hline $\begin{array}{l}\text { showed thru action } \\
9 \%\end{array}$ & & $\begin{array}{l}\text { none } \\
86 \% \\
\end{array}$ & $\begin{array}{l}\text { complied } \\
2 \% \\
\end{array}$ & $\begin{array}{l}\text { moved to face } \\
0.3 \%\end{array}$ \\
\hline $\begin{array}{l}\text { informed superior } \\
1.7 \%\end{array}$ & & & $\begin{array}{l}\text { continued behavior } \\
1 \%\end{array}$ & $\begin{array}{l}\text { hit } \\
0.3 \% \\
\end{array}$ \\
\hline
\end{tabular}

$\mathrm{n}=\mathbf{3 0 0}$

A small percentage $(4.3 \%)$ of the participants responded with what the researcher categorized as relationship-building responses such as asking questions, apologizing for the offense, explaining, listening, or being friendly. Six percent of the participants 
dealt with the situation in an indirect manner and sometimes in ways that could be categorized as appeasing or placating responses such as diverting the conversation, agreeing with the discriminator, laughing at a discriminatory joke, smiling, biting one's tongue or remaining silent, ignoring the offense, crying, shaking one 's head at the offense, complying with the request even though it seemed discriminatory, or continuing on as though the offense never occurred.

The researcher recognizes that arguments could be made for the placement of responses in more than one category and a defense could be made for moving some responses to other categories. The labels of the categories and the typology itself is only one possibility of many and arguments could be made for the other possibilities as explanatory conceptualizations. This having been said, the researcher suggests that this conceptualization does lead to some important observations.

For example, when participants did confront the discrimination, they most often did so by telling people something, i.e. telling their thoughts and feelings, telling their own ethnicity to confront the discriminator with the discrimination, telling others what the discrimination laws are, or telling the other they did not want them to make that kind of comment or engage in that behavior. An interesting follow-up question might be to ask what makes it possible for these people to confront perceived discrimination by engaging in self-disclosure like revealing their own ethnicity or telling their thoughts and/or feelings, and what factors contribute to some people feeling confident enough to either ask someone else not to say or do the offensive behavior or advise someone of discrimination laws. If an organization provides information about discrimination laws, and provides training in that area might this inspire confidence? If informing people about discrimination is part of the job description, might people advise others as to discrimination laws more frequently. 
The questionnaire in this study did not ask participants their reasons for feeling or acting in the ways they did. Implications \#2, \#3, and \#4 in the Implications for Future Study section address these issues.

\section{Assumptions}

Participants identified the situation in their description as discriminatory, and as Table IVX suggests, participants made judgments or attributions about behavior they perceived as discriminatory behavior $42 \%$ of the time.

TABLE XIV

Thoughts and Feelings about the Situation

\begin{tabular}{|l|l|l|l|}
\hline $\begin{array}{l}\text { Judgment or } \\
\text { Attribution }\end{array}$ & Description & Other & No Thoughts \\
\hline $42 \%$ & $33 \%$ & $5 \%$ & $20 \%$ \\
\hline $\begin{array}{l}\text { judge behavior/attitude } \\
17 \%\end{array}$ & $\begin{array}{l}\text { explain } \\
11.7 \%\end{array}$ & $\begin{array}{l}\text { kept thinking } \\
\text { bbout it } \\
2.7 \%\end{array}$ & $\begin{array}{l}\text { none } \\
16.3 \%\end{array}$ \\
\hline $\begin{array}{l}\text { attribute to character } \\
14 \%\end{array}$ & $\begin{array}{l}\text { identified as prejudice } \\
\text { or discrimination } \\
8.3 \%\end{array}$ & $\begin{array}{l}\text { accepted } \\
2 \%\end{array}$ & $\begin{array}{l}\text { didn't think } \\
\text { bout it } \\
4 \%\end{array}$ \\
\hline $\begin{array}{l}\text { judge self } \\
6.3 \%\end{array}$ & $\begin{array}{l}\text { philosophize/social comment } \\
13.4 \%\end{array}$ & & \\
\hline $\begin{array}{l}\text { what should be } \\
2.3 \%\end{array}$ & & & \\
\hline attribute characteristic \\
$2 \%$
\end{tabular}

Most of these perceptions, attributions, and judgments seemed to be made without any input from others involved in the incident. According to the researcher's perceptions of the data, participants engaged in perception checking (categorized in this study as asking questions) only $3 \%$ of the time, and the participants reported that they listened only $3 \%$ of the time. It seems that most of the time a perception of the incident and meaning-making about the incident occurred from the perspective of the participant 
only. If a comment or behavior was perceived by the participant to be discriminatory, one effective response would be to offer feedback about how the participant was interpreting the incident and then ask for feedback. In this study, many of the participants responded by saying something, or by giving feedback regarding the interaction. Effective feedback is descriptive rather than judgmental, specific rather than vague and addresses the needs and values of both people. Although this study does not include a thorough analysis of the feedback, the category labels of the assertive verbal responses (asked not to say, stated thoughts and feelings, stated own ethnicity, and advised of discrimination laws) suggest doubt that the responses addressed the needs and values of both people.

The literature on effective listening suggests that acknowledging the other person, perception checking, paraphrasing and questioning are effective responses. Mayer (1989) tells us that effective listening is one of the most helpful responses to difficult interactions, yet the responses most often described by participants were selffocused as they reported their own judgments, feelings, or thoughts without asking for input from others.

When perceptions are not checked, one outcome is that no opportunity is given for others involved in the situation to explain their intentions, to recognize that something they have said or done has been interpreted as discriminatory, or to learn about how others think and feel about their actions. An assumption was made and a future way of interacting with that person determined without the knowledge of the person performing the offensive behavior.

In effect, the offending person is silenced. There has been no opportunity to explain a different perspective or intentions, no opportunity has occurred to discuss possible cultural differences, and no opportunity for relational repair. The person 
engaging in the offensive behavior may have little or no understanding the she or he has been judged and condemned and a wall or barrier erected. If the response to an unthinking remark, an inept attempt at humor, or even an outright prejudicial statement, is to be judged and mentally dismissed as not worthy of being respected, valued or listened to, discrimination is perpetuated. The thoughts, feelings, and experiences of the person who offended are disregarded and the offender is silenced in the mind and future actions of the person who was offended.

Largely, participants did not report physical or nonverbal strategies. The most often reported nonverbal strategy $(8.3 \%)$ was to ignore the incident. Thus, descriptions of the interaction were minimal and did not include nonverbal components of the interaction. This is interesting because one might expect that if an incident were memorable enough to be reported, the participant would react in some way. One common saying in communication is that "you cannot not communicate." If the participants were involved in this incident in any way, even their silence, their posture, or their nonresponse was a response. The researcher posits that the participants who indicated they said or did nothing and provided no nonverbal description did not realize that saying or doing nothing was "doing" something. This may be interesting discussion prompt for diversity trainers to use in addressing what constitutes communication.

Ineffective listening includes responses such as ambushing, ignoring, forming a retort, and having a closed mind. In this study, $8 \%$ of the nonverbal responses were ignoring. Six percent of the verbal responses included cursing. embarrassing the other and making a come-back remark and could be understood as forming a retort 


\section{Relationship-Building Responses Needed}

Participants in this study utilized what the researcher categorized as relationship-building responses only $4.3 \%$ of the time. Considering that most of the discriminatory situations occurred in long-term relationships, one might hope for many participants to engage in relationship-building responses. Using Gibb's categories for creating confirming climates, one would expect participants to spontaneously or honestly and openly respond by describing their feelings and thoughts to the other without judgment; respond with empathy and ask the other about their experiences; take an equal stance rather than a superior judgmental stance in the interaction; respond with a provisional attitude and state how they see the situation but ask for another interpretation with openness to hearing other interpretations; and respond to the situations as an opportunity for problem solving in which people can work together to address an issue and work out a way to interact with more satisfaction for both.

One way of assessing the response is to ask where responsibility is located. "You" language locates responsibility in someone else and results in attributions to character and judgments about fault. "I" language takes responsibility for thoughts and feelings about an interaction and attributes more often to situation and circumstances. Although specific "I" and "you" language is not identified in this study, some comments can be made about the location of responsibility in the participants descriptions of their thoughts. A little over thirteen percent of the time the participants make a philosophical or social comment. These responses most often indicated the participant was attributing the incident to the situation and social forces. A little over six percent of the time the participant judged him or herself, taking at least some responsibility for the incident. Seventeen percent of the time participants attributed or judged the behavior, but not the person. Fourteen percent of the time the 
participant attributed the incident to the person's characteristics. Most often, the responses in this category were name-calling or labeling responses. Two percent of the time, participants' still attributed the incident to a characteristic about the person, but the comments were more descriptive than judgmental in connotation. Thus, when responsibility could be assessed, which was about half of the time $(52.7 \%)$, most of the participants' (36.7\%) attributed the incident to situational characteristics (i.e. lack of understanding or education). Only $16 \%$ of the time did participant's attribute the incident to the person's disposition or character. In building affirming climates, it is important to validate the skills people already possess. If a large number of people come to diversity training already prepared to share responsibility and to make situational attributions, these skills could be encouraged and validated.

\section{What Might Have Respondents Done Differently?}

In answer to the question "What could you have said or done differently in that situation" the researcher utilized the same typology and categories developed earlier in response to the question about how participants' managed situations (see Table XIII). The categories included assertive responses; relationship building responses; indirect, appeasing or placating responses; defensive or aggressive responses; and lack of response.

Seventeen percent answered "nothing," $12 \%$ said "not sure" or "unknown," and $56.7 \%$ did not respond to the question resulting in $85.7 \%$ in the lack of response category. Of the participants who offered alternatives, $10 \%$ suggested either assertive or relationship-building responses and $4 \%$ responded with defensive, aggressive, indirect, placating, or appeasing responses. 
It is interesting to note how participants managed their incidents and then the alternatives they suggested after they thought about the incident. A little over twelve percent managed their situation assertively and $6 \%$ suggested assertive choices as an alternative. Four percent managed their situation with relationship-building responses and $4 \%$ suggested relationship-building choices. Over six and a half percent managed the situation with indirect or placating responses and 3\% suggested these responses as an alternative. Three percent managed the situation with defensive or aggressive responses and $1 \%$ suggested these as alternatives. Seventy three percent either didn't respond or didn't report their response and $85 \%$ were silent as to alternatives to their actions.

\section{Cultural Difference in Channel Preference}

Different people may prefer different channels for conveying sensitive messages. Judgments made about choices must be considered in light of intercultural differences. In this study, there was a difference in the suggesting of possible communication channels by race/ethnicity. When asked what they could have done differently, seven members of Hispanic, Asian, and Native American groups suggested they could have written letters while no European-Americans and no AfricanAmericans suggested this channel (See Table XV). Nine European-Americans and one African-American went to their supervisors while no Hispanic, Asian or NativeAmericans went to their supervisors. Without some understanding of cultural differences, assumptions and judgments may be made about the people responding to a discriminatory incident based on their choice of channel.

Communication competence refers to the ability to communicate effectively and appropriately with other people (O'Hair \& Friederich, 1992). Selecting an 
TABLE XV

Could Have Done Differently

\begin{tabular}{|c|c|c|c|c|}
\hline $\begin{array}{l}\text { Assertive } \\
\text { Response } \\
6 \% \text { overall }\end{array}$ & $\begin{array}{l}\text { Relationship } \\
\text { Building Response } \\
4.2 \% \text { overall }\end{array}$ & $\begin{array}{l}\text { Lack of } \\
\text { Response } \\
85.7 \% \text { overall }\end{array}$ & $\begin{array}{l}\text { Indirect or Appeasing/ } \\
\text { Placating Responses } \\
3.2 \% \text { overall }\end{array}$ & $\begin{array}{l}\text { Defensive/Aggressive } \\
\text { Response } \\
0.9 \% \text { overall }\end{array}$ \\
\hline \multicolumn{5}{|l|}{ VERBAL } \\
\hline $17.3 \%$ & $6 \%$ & $75 \%$ & $0 \%$ & $1.7 \%$ \\
\hline $\begin{array}{l}\text { asked not to say } \\
2.7 \%\end{array}$ & $\begin{array}{l}\text { asked questions } \\
2 \%\end{array}$ & & & $\begin{array}{l}\text { escalated the situation } \\
1.7 \%\end{array}$ \\
\hline $\begin{array}{l}\text { stated thoughts/feeling } \\
9 \%\end{array}$ & $\begin{array}{l}\text { talked } \\
1 \% \\
\end{array}$ & $\begin{array}{l}\text { no/other } \\
75 \%\end{array}$ & & \\
\hline $\begin{array}{l}\text { pointed out the discrim } \\
4.7 \%\end{array}$ & $\begin{array}{l}\text { explained } \\
3 \%\end{array}$ & & & \\
\hline \multicolumn{5}{|l|}{$\begin{array}{l}\text { talked to someone about it } \\
1 \%\end{array}$} \\
\hline \multicolumn{5}{|l|}{ NONVERBAL } \\
\hline \multirow[t]{7}{*}{$0 \%$} & $0 \%$ & $90.7 \%$ & $9.3 \%$ & $0 \%$ \\
\hline & & none $90.7 \%$ & let it pass, ignore $4 \%$ & \\
\hline & & & not laughed $0.7 \%$ & \\
\hline & & & $\begin{array}{l}\text { managed emotions } \\
\text { better } 3.7 \%\end{array}$ & \\
\hline & & & $\begin{array}{l}\text { complied } \\
0.3 \%\end{array}$ & \\
\hline & & & $\begin{array}{l}\text { dress differently } \\
0.3 \%\end{array}$ & \\
\hline & & & $\begin{array}{l}\text { kept distance } \\
0.3 \% \\
\end{array}$ & \\
\hline \multicolumn{5}{|l|}{ ACTION } \\
\hline $5.9 \%$ & $0 \%$ & $89 \%$ & $3.3 \%$ & $1.6 \%$ \\
\hline $\begin{array}{l}\text { wrote letter } \\
2.3 \%\end{array}$ & & $\begin{array}{l}\text { none } \\
89 \% \\
\end{array}$ & $\begin{array}{l}\text { walked away/hung up } \\
2.3 \%\end{array}$ & $\begin{array}{l}\text { moved to face } \\
0.3 \%\end{array}$ \\
\hline $\begin{array}{l}\text { have a meeting addressing } \\
\text { discr. } 0.3 \%\end{array}$ & & & $\begin{array}{l}\text { lied on application } \\
0.3 \%\end{array}$ & $\begin{array}{l}\text { hit person, throw out } \\
1.3 \%\end{array}$ \\
\hline $\begin{array}{l}\text { went to supervisor } \\
3.3 \%\end{array}$ & & & $\begin{array}{l}\text { changed physical } \\
\text { location } 0.7 \%\end{array}$ & \\
\hline \multicolumn{5}{|l|}{ THOUGHTS } \\
\hline $1 \%$ & $10.6 \%$ & $88 \%$ & $0 \%$ & $0.3 \%$ \\
\hline $\begin{array}{l}\text { offer an alternative } \\
0.3 \%\end{array}$ & $\begin{array}{l}\text { continued to work } \\
\text { on } \\
8.3 \%\end{array}$ & $\begin{array}{l}\text { none } \\
54 \%\end{array}$ & & $\begin{array}{l}\text { what other should do } \\
0.3 \%\end{array}$ \\
\hline \multirow[t]{3}{*}{$\begin{array}{l}\text { been more specific } \\
0.7 \%\end{array}$} & $\begin{array}{l}\text { supported somehow } \\
1 \%\end{array}$ & $\begin{array}{l}\text { "nothing" } \\
17 \%\end{array}$ & & \\
\hline & $\begin{array}{l}\text { something, not } \\
\text { specific } 1.3 \%\end{array}$ & $\begin{array}{l}\text { "not sure" or } \\
\text { "unknown"12\% }\end{array}$ & & \\
\hline & & satisfied $5 \%$ & & \\
\hline
\end{tabular}

$n=300$ 
appropriate channel to communicate an incident involving discrimination may be a difficult task. O'Hair \& Friederich (1992) suggest that rich media such as face-to-face speaking or using the telephone are the most appropriate channels "when the situation stressful, when the message is vague or difficult to understand, and when personal information is to be conveyed (p. 60)." According to this description, it would seem most appropriate to addressing a discriminatory incident in a face-to-face encounter such as talking to the supervisor. Mortenson notes that written channels are more likely to gain accountability and the receiver will have increased responsibility for responding to a written message. Mortenson also points out that situations that are more formal; that require "prescribed actions and behaviors and allow little deviation from those norms frequently cause anxiety (p. 63)."

Thus, letter writing could be perceived as more formal, results in increased responsibility for responding, and therefore, causing increased anxiety on the part of the manager receiving the letter.

However, in making decisions about selecting an appropriate channel, it is important to realize that "communication networks, when viewed in the most inclusive way, are products of culturally defined patterns of behavior (Mortensen, 1972, p. 350)." Culture refers to the "patterned ways of behaving, feeling and reacting" (Mortenson, p. 350). As Mortenson points out:

The constraining impact of culture is not limited solely to the number of connections and the potential range of contacts that are possible with members of one culture and another. Its influence also extends the way messages are transmitted and interpreted in a given cultural setting. The implicit rules of culture restrict the timing, protocol, style, and content of information exchanged by various groups and classes of people (Mortenson, p. 130)."

There are U.S. cultural rules regarding the selection of an appropriate channel. Managers may prefer that people with problems come in and talk about them before 
they grow out of proportion or get passed on to higher-ups. Hence, the informality of the open-door policy in which employees are expected to come in and talk to managers about problems, and the "chain-of-command" rule in which employees are expected to take problems to the immediate superior rather than people higher up in the hierarchy.

African-American and European-Americans may be said to be more lowcontext, or, in other words, more reliant upon and appreciative of the verbal component in a communication context, while Hispanic-Americans, Asian-Americans, and Native Americans may be said to be more high-context, or more reliant upon and appreciative of the nonverbal and indirect components of a situation. Hence, it may be that African and European Americans may find more overt verbal communication less threatening and preferable while Hispanic, Asian and Native Americans might find the written channel less threatening.

Of concern might be US dominant interpretations of the utilization of a written communication channel to address discrimination. As pointed out above, in U.S. organizations, informal communication channels might be preferred in these situations. The written communication channel, demanding more formal accountability may be perceived as threatening. Yet, it is less confrontative and gives the person time to think carefully about their response. It is important to understand the different factors impacting channel selection by different groups and the possible assumptions and judgments that might be made without sufficient cultural knowledge.

\section{Range of Perceived Options}

Ninety two percent of the people in this study could identify a discriminatory incident, but most did not report effective responses at the time of the incident; most did not identify effective alternative choices after they had time to think about it; most 
reported feeling angry, bothered, hurt, or embarrassed in relation to the incident; and only $5 \%$ reported that they were satisfied with the way they handled the incident.

This ineffectiveness combined with the negative feelings may lead to further avoidance when difficult interactions occur. One of the most powerful themes to emerge in this study was that most of the participants reported negative feelings about the incident, and so few offered alternative possibilities for addressing the incident.

When asked "what could you have said or done differently?" $29 \%$ wrote "nothing," "not sure" or "unknown" and another 54\% offered no thoughts on what they could have done differently. Ninety percent offered no physical or nonverbal alternatives and $75 \%$ offered no verbal alternatives. Yet, $68 \%$ of the feelings reported in relation to the incident were negative and only $5 \%$ of the participants reported that they felt satisfied after the incident.

This relates to the earlier reported comment that participants were able to identify a discriminatory incident but were less sure about how to effectively manage or address the incident. Since there an endless number of possible communication choices in any situation, one would expect people to report a variety of possibilities in answer to the question "What could you have said or done differently?" Instead, one third of the participants were unsure or perceived there to be nothing they could have said or done differently. Participants did not perceive the wide range of communication choices possible in any situation, they did not feel satisfied or positive about the outcome of the situation, and they did not view the incident as an opportunity to create or build relationships. 


\section{Literature Review: Gap Related to the Structural Approach}

As suggested in the literature review, the structural approach to understanding the dynamics of discrimination suggests that societies develop social norms which encourage or discourage tolerance. The current economic and social ordering structure of Western cultures is founded upon the dynamic of competitiveness and a win-lose understanding of how the world works (Schaefer, 1988). As long as different groups view life as a zero-sum game in which the gain of one person or one group automatically results in a loss for another person or group, racism is the structural result (Schaefer, 1988). Thus, current organizational cultures which are embedded in a social structure based on this capitalistic theme of competitiveness are likely, at some level, to encourage prejudice and discrimination. It is highly likely that this dynamic is hidden, since the United States also espouses a commitment to equality.

When reviewing the literature around discrimination and the workplace this researcher was expecting to find a discussion of the current social climate and the modalities of the situations. Modalities of situations "refers to those behavioral conditions that exist because of the structural constraints of the interaction setting" (Asante \& Gudykunst, 1989, p. 378). Asante and Davis identify modalities which affect the workplace, including hierarchy, status, space, gender.

In reviewing the literature, it becomes apparent that the issue of discrimination is addressed at several levels, including the EEO and AA policy level which attempts to address historical equity issues; the sociological level in which the processes of prejudice and discrimination are explained as social phenomenon; the psychological level in which attitude formation and change are addressed; and program level in which diversity training programs are devised to address levels of understanding and behavior. There is a great deal of theory explaining different facets of the social 
practice of discrimination. However, there is limited literature describing what discrimination looks like in the workplace and describing organizational members' strategies and attitudes in dealing with discrimination with respect to existing organizational cultures and the modalities which affect the workplace. The question of how people make decisions about managing discrimination considering existing power structures has not been adequately described. People need to understand their options and consequences, as well as the interpersonal and intercultural aspects provided in training.

There is literature on interpersonal and intercultural skills, as the reflected in the diversity training review. There is literature on "backlash" to diversity training programs, and there is organizational literature on change in organizations. What was not found, however, are descriptive studies that report how organizations may support or suppress discrimination at an interpersonal level or that analyze variables which may contribute to the comfort and skill used in responding to discrimination.

While contemplating this study and the lack of literature describing organizational members experiences dealing with discrimination, questions which come to mind include whether or not organizational members respond to perceived discrimination differently based on organizational factors such as their position within the hierarchy, the amount of training they have had in dealing with discrimination, whether or not there are protocols for confronting perceived discrimination, the organizational norms around prejudice and discrimination, their familiarity with the person who engages in discrimination, the level of prejudice perceived, the context, the gender mix in a group where discrimination is perceived, the number people from co-cultures in the organization, etc. These are all possible questions which could be addressed in future studies. 


\section{Implications for Organizations and Diversity Trainers}

One goal of this study was to provide information that can be utilized by organizations and by diversity trainers in designing future diversity programs. This section provides a summary of interesting themes and an overview of implications for organizations and diversity trainers. For example, $92 \%$ of the people in this study could identify a discriminatory incident, but most did not report effective responses to the incident; most did not identify effective alternative choices after they had time to think about it; most reported feeling angry, bothered, hurt, or embarrassed in relation to the incident; and only $5 \%$ reported that they were satisfied with the way they handled the incident. These themes and their resulting implications are summarized in table XVII.

\section{Contexts}

It may be helpful for diversity trainers to know what kinds of responses participants made in the different contexts.

\section{Ongoing Relationships}

For example, two-thirds of the discriminatory incidents remembered in this study involved a person of some significance in the participant's life and one-quarter of the time participants recalled an incident in which there was some relationship such as customer, professional, acquaintance, or customer service situation. The communication choices most people made were in the context of an ongoing relationship. Diversity trainers may want to focus on interpersonal skills addressing discrimination in the context of ongoing significant relationships. It may be especially important to address the power and group issues in this context. 
Settings

Incidents were reported more often in business settings and less often at home or with friends. Diversity trainers may find it helpful to ask participants in what settings they most often recognize discriminatory incidents and in which settings is it most difficult to confront the incidents. Diversity trainers may want to discuss the role a setting may play in limiting or encouraging particular responses.

\section{Types of Discrimination}

The most memorable discriminatory incidents were about gender or race/ethnicity. Gender, race and ethnicity can still be very loaded interactions. This suggests the importance of both organizations and diversity trainers nurturing the types of communication skills needed when discussing sensitive topics as well as the continued need to encourage awareness around issues of gender, race, and ethnicity. Also, since respondents most often thought of discriminatory incidents as involving gender, race or ethnicity, it may be interesting for diversity trainers to ask how may types of discrimination participants do actually recognize and include a discussion of the types of discrimination beyond gender, race and ethnicity.

\section{Reframe Conflict or Discrimination as "Opportunity"}

Realizing that participants in this study most often recalled discriminatory incidents in the context of ongoing relationships, it may be helpful for diversity trainers to 1) provide participants with discussion of the different issues that may arise depending on the type of relationships with special attention to conflict management in the context of relationship development; and 2) reframe conflict and discrimination as opportunities for relationship development. Gibb's suggestion of creating a confirming communication climate by taking a problem-solving orientation may be 
especially pertinent here. Diversity trainers may want to emphasize the positive possibilities represented by an incident involving discrimination. If conflict were not perceived as such a threat to relationships, fears of exclusion or ostricization may not act so strongly as barriers which limit responses. As Wile (1988) suggests, incidents which stimulate conflict may, instead, provide impetus for discussion and learning and create opportunities for developing relationships.

\section{Assumptions}

Participants need to develop skills in listening and perception checking. Participants described many perceptions, attributions, assumptions, and judgments, but very few did any question-asking or listening to check the accuracy of their perceptions. Participants identified the situation in their description as discriminatory, and made judgments or attributions about behavior they perceived as discriminatory behavior $42 \%$ of the time. Most of these perceptions, attributions, and judgments seemed to be made without any input from others involved in the incident.

\section{Relationship Building and Assertive Responses Needed}

Participants need skills in responding assertively, and in developing expertise in relationship-building responses. Even though assertive responses were the most frequent of any management strategy, they still occurred only $12.3 \%$ of the time. Realizing the limited frequency of assertive responses may be helpful information for organizations and diversity trainers. When participants did confront the discrimination, they most often did so by telling people something, i.e. telling their thoughts and feelings, telling their own ethnicity to confront the discriminator with the discrimination, telling others what the discrimination laws are, or telling the other they did not want them to make that kind of comment or engage in that behavior. Organizations and diversity trainers may want to explore what makes it possible for 
people to confront perceived discrimination by engaging in self-disclosure like revealing their own ethnicity or telling their thoughts and/or feelings, and what factors contribute to some people feeling confident enough to either ask someone else not to say or do the offensive behavior or advise someone of discrimination laws. In this study, advising people about discrimination laws was part of the job responsibilities of many organizational members. Thus, established protocols for informing clients may have supported particular responses. Might it inspire confidence if an organization provides information about discrimination laws, and provides training in that area? If informing people about discrimination is part of the job description, might people advise others as to discrimination laws more frequently?

\section{Responsibility}

In describing the setting, participants often reported the type of communication interaction involved. In this study, participants responded to discrimination less often in group and observing situations than in individual situations. More than half of the time, the participant was involved in the interaction, possibly increasing the perceived responsibility for choosing a communication response. More than a quarter of the time the participant was more removed from the interaction as part of a group or an observer, thus possibly decreasing responsibility for directly confronting the discriminatory incident. It may be that a participant would more often recall an incident as significant if it was one in which they felt more direct responsibility for addressing the perceived discrimination.

It may be that the more direct responsibility perceived, the more likely a participant would speak up directly. It is also possible that group norms and social norms limit any type of confrontive response. Since participants responded to 
discrimination less often in group and observing situations, trainers could address the factors involved and the special difficulties inherent in these situations.

In this study, when the participants' orientation towards the location of responsibility could be assessed, which was about half of the time, participants' often attributed the incident to situational characteristics (i.e. lack of understanding or education). Only $16 \%$ of the time did participant's attribute the incident to the person's disposition or character. This is a helpful finding for diversity trainers. In building affirming climates, trainers need to validate the skills people already possess. If a large number of people come to diversity training already prepared to share responsibility and to make situational attributions, diversity trainers could look for this and validate this in their trainees.

\section{Reframe Incidents as Learning Opportunities}

As mentioned earlier, while most of the people in this study could identify a discriminatory incident, most did not report effective responses to the incident; most did not identify effective alternative choices after they had time to think about it; most reported feeling angry, bothered, hurt, or embarrassed in relation to the incident; and only $5 \%$ reported that they were satisfied with the way they handled the incident.

It is hoped that this description of organizational members' average encounter with a discriminatory incident may be useful information for diversity trainers. In public speaking classes, instructors and texts often start off by pointing out that public speaking is most college students' greatest fear. Students find it embarrassing to practice this skill publicly and may be ashamed of their sometimes inept, awkward, and unskilled behaviors. Realizing that so many people feel anxious and embarrassed in this situation often relieves some of the fear and shame. 
Similarly, people who recall discriminatory incidents may be embarrassed to acknowledge their inept responses and may feel ashamed if they have strong beliefs about the issues of discrimination but did not respond effectively to an incident they perceived as discriminatory. This shame or embarrassment may function as an internal barrier to learning about more effective responses. The descriptions of responses in this study could be used as a discussion prompt. Trainees could compare their own experiences with the experiences of the members in this study. If diversity trainers present their trainees with the above description of organizational members' experiences with discriminatory incidents, trainees may realize that many people have difficulty responding effectively, that people often respond in inept ways, and that many people go away these incidents with negative feelings. Trainees may not be so embarrassed to discuss their own encounters if they realize their experiences are typical. People may gain more from training if they can honestly acknowledge report their own, sometimes embarrassing experiences. Reframing these experiences as incidents from which to learn may help dissipate some of the residual negative feelings associated with past incidents and allow people to move to the more constructive activity of determining effective responses.

\section{Cultural Differences in Channel Preference}

Of concern might be U.S. dominant interpretations of the utilization of a written communication channel to address discrimination. As pointed out earlier, in U.S. organizations, informal communication channels might be preferred in these situations. The written communication channel, demanding more formal accountability may be perceived as threatening. Yet, it is less confrontative and gives the person time to think carefully about their response. Diversity trainers may want to 
discuss the different channels utilized by different groups and the possible assumptions and judgments that might be made without sufficient cultural knowledge.

\section{Relative Ability to Identify and Analyze}

As mentioned earlier, it may be that participants can identify discrimination because of the gut or feeling level experience that accompanies the incident. However, the type of analysis necessary to choose a strategy for action requires bridging the gap between feeling knowledge that something happened and an analytic knowledge of assessing situations and choosing actions. Diversity trainers may want to start with the tacit knowledge that something uncomfortable happened and build on that understanding. Diversity trainers can provide people with tools to move from the level of identification to descriptive, analytic, and action modes.

\section{Range Of Perceived Options}

One of the most powerful themes to emerge in this study was that most of the participants reported negative feelings about the incident, and so few offered alternative possibilities for addressing the incident. Most participants did not respond effectively at the time of the incident and the range of choices perceived after thinking about it was still limited. This relates to the earlier reported comment that participants were able to identify a discriminatory incident but were less sure about how to effectively manage or address the incident.

Since there an endless number of possible communication choices in any situation, one would expect people to report a variety of possibilities in answer to the question "What could you have said or done differently?" Instead, one third of the participants were unsure or perceived there to be nothing they could have said or done differently. Participants did not perceive the wide range of communication choices 
possible in any situation. This lack of knowledge combined with the negative feelings may lead to further avoidance when difficult interactions occur. Diversity trainers may want to talk about this circular problem. 


\section{TABLE XVI}

\section{Themes of Interest and Implications}

\section{ONGOING RELATIONSHIPS}

Participants most often recalled discriminatory incidents involving ongoing relationships. Diversity trainers may want to focus on interpersonal skills addressing discrimination in the context of ongoing relationships.

Especially important would be to address the power and group issues in this context.

\section{TYPES OF DISCRIMINATION}

The most memorable discriminatory incidents were about gender or race/ethnicity. Gender. race and ethnicity can still be very loaded interactions. It may be interesting to find out in future research to find out how may types of discrimination participants recognize.

\section{REFRAME CONFLICT OR DISCRIMINATION AS OPPORTUNITY}

Participants reported negative feelings in response to conflict and discrimination. The situation was not seen as an opportunity for building relationships or problem solving. Diversity trainers may want to reframe conflict as "opportunity."

\section{ASSUMPTIONS}

Participants described many perceptions, attributions, assumptions, and judgments, but very few did any question-asking or listening to check the accuracy of their perceptions.

\section{RELATIONSHIP BUILDING AND ASSERTIVE RESPONSES NEEDED}

Participants need skills in responding assertively, and in developing expertise in relationship-building responses.

\section{RESPONSIBILITY}

Participants responded to discrimination less often in group and observing situations. Trainers could address the factors involved and the special difficulties inherent in these situations.

\section{REFRAME INCIDENTS AS LEARNING}

Participants recall the negative aspects of the interaction. Diversity trainers could focus on reframing the incidents as learning incidents.

\section{CULTURAL DIFFERENCES IN CHANNEL PREFERENCE}

Different people may prefer different channels for conveying sensitive messages. Judgments made about choices must be considered in light of intercultural differences.

\section{ABLE TO IDENTIFY, DIFFICULTY WITH ANALYSIS}

Participants seemed able to identify a discriminatory incident but had difficulty analyzing the situation to choose a communication strategy.

\section{RANGE OF PERCEIVED OPTIONS}

Most participants did not respond effectively at the time of the incident and the range of choices perceived after thinking about it was still limited. This ineffectiveness combined with the negative feelings may lead to further avoidance when difficult interactions occur. Diversity trainers may want to talk about this circular problem. 


\section{Limitations of This Study}

This study is subject to several limitations, including the following:

1. The questionnaire may not measure how respondents actually behaved and what they actually said and did (Arnold \& McClure, 1989). The respondents report their own perceptions of what they said and did. Respondents may tend to specifically recall incidents associated with negative feelings;

2. The questionnaires ask for recall and reflection and therefore, for subjects to remember and interpret their behavior;

3. Subjects' perceptions may conform to expectations, resulting in socially acceptable data (Frey et al, 1991);

4. People who return questionnaires may differ from rest of population and bias the sample (Miller, 1991);

5. The questions address possibly unpleasant or ego-threatening incidents and people may therefore, report them inaccurately (Frey et al., 1991); and,

6. The researcher decides what is significant and what is not. Researcher bias, perception and knowledge is reflected in the results of the study.

\section{Implications for Future Study}

Lalonde and Cameron ( $p$ 281) suggest that "one challenge to future research is to identify the conditions that bring about an acknowledgment of personal discrimination when it occurs." One possibility in addressing this question would be to select all the participants who identified an incident in which the discrimination was directed at themselves and analyze these incidents to identify any conditions which caused the person to acknowledge the personal discrimination.

In addition, the following notes some issues for future consideration and suggests possible research questions about responses to discriminatory incidents:

1. In this study, contextual factors such as ongoing relationships, the setting, and composition of the interactants seemed related to responses chosen by participants and types of discrimination described. Possible future research 
questions may include: In what settings do participants most often recognize discriminatory incidents? and, in which settings is it most difficult to confront the incident?

2. In this study, advising people about discrimination laws was part of the job responsibilities of many organizational members. Thus, established protocols for informing clients may have supported this particular response. Future studies may wish to ask: Is there a relationship between job responsibilities and related protocols for addressing discrimination and the frequency of certain kinds of responses. For example, if informing people about discrimination is part of the job description, might people advise others as to discrimination laws more frequently?

3. If an organization provides information about discrimination laws, and provides training in that area, does this increase the frequency of some kinds of responses?.

4. The questionnaire in this study did not ask participants their reasons for feeling or acting in the ways they did. A follow-up study might ask about the factors which influenced their ability to respond assertively.

5. How do organizations support or suppress discrimination at an interpersonal level? Questions may include: how do participants make decisions about communication choices considering modalities such as hierarchy, status, space, and gender; how do participants make decisions about managing discrimination considering existing power structures; and how do people understand their options and consequences within a political framing of the interaction.

In other words, do organizational members respond to perceived discrimination differently based on organizational factors such as:

- their position within the hierarchy,

- the amount of training they have had in dealing with discrimination,

- whether or not there are protocols for confronting perceived discrimination,

- the organizational norms around prejudice and discrimination,

- their familiarity with the person who engages in discrimination, 
- the level of prejudice perceived,

- the context,

- the gender mix in a group where discrimination is perceived,

- the number people from co-cultures in the organization, etc.

These are areas which have not received much attention and which could be addressed in future studies. These studies would contribute to the ever increasingly important areas of intercultural communication and diversity training. 


\section{REFERENCES}

Adler, R. B. \& Rodman, G. (1991). Understanding Human Communication. Fort Worth: Holt, Rinehart \& Winston, Inc.

Anderson, B., \& Nilsson, S. (1964). Studies in the reliability an validity of the critical incident technique. Journal of Applied Psychology, 48, 398-403.

Arnold, W. E. \& McClure, L. (1989). Communication Training \& Development. New York: Harper \& Row, Publishers.

Alderfer, C. P., Alderfer, C. J., Bell, E. L. \& Jones, J. (1992). The race relations competence workshop: theory and results. Human Relations. 45 (12), 12591291.

Almquist, E. M. (1989). The experiences of minority women in the United States: Intersections of race, gender, and class. In L. D.

Cain, (Ed.). The Emerging Minorities. Dubuque: Kendall/Hunt Publishing Company.

Bandura, A. (1982). Self-efficacy mechanism in human agency. American Physiologist. 37, (2). 122-147.

Bandura, A. (1977). Self-efficacy: toward a unifying theory of behavior change. Psychological Review. 84, (2). 191-215.

Bramley, P. (1991). Evaluating Training Effectiveness. London: McGraw-Hill Book Company.

Brislin, R. \& Triandis, H. (1977). Tests of the effectiveness of cultural learning experiences. Paper.

Brislin, R. \& Yoshida. (1994). Intercultural Communication Training. In Press.

Bowman, J. E. (1978). The evaluation of overseas educational programs. Paper presented to International Studies Association.

Bracken, D. W. (1992). Benchmarking employee attitudes. Training \& Development. June, 49-53.

Caudron, S. (1990). Monsanto Responds. Personnel Journal. November, 72-80. 
Caudron, S. (1993). Training can damage diversity efforts. Personnel Journal, 72(4), 54-64.

Cox, T. H. \& Blake, S. (1991). Managing cultural diversity: Implications for organizational competitiveness. Academy of Management Executive. 5 (3), $45-56$.

De Valk, S. (1993). Holding up a mirror to diversity issues. Training \& Development, 47(4), 11-13.

DeVito, J. A. (1994). Human Communication. New York: HarperCollins College Publishers.

Delatte, A. P. \& Baytos, L. (1993). 8 guidelines for successful diversity training. Training, 30(1), 55-60.

Duley, J. S. (1975). Critical incident writing. Communique, 5, (3 \& 4)

Fielding, N. G. \& Fielding, J. L. Linking Data. Newbury Park: Sage.

Frankel, J. R. \& Wallen, N. E. (1993). How To Design and Evaluate Research In Education. New York: McGraw-Hill.

Frey, L. R., Botan, C. H., Friedman, P. G., \& Kreps, G. L. (1991). Investigating Communication: An Introduction to Research Methods. Englewood Cliffs: Prentice Hall.

Flanagan, J. C. (1954). The critical incident technique. Psychological Bulletin. 51 (4) $327-358$.

Geber, B. (1990). I give up: is it valuing diversity or managing diversity? Training: The Magazine of Human Resources Development, 27 (7), 26-27.

Geiger, A. H. (1992). Measures for mentors. Training \& Development. February, p. 65-67.

Goddard, R. W. (1989). Workforce 2000. Personnel Journal. Feb, 65-71.

Gordon, J. (1992). Getting started on 'diversity work.' Training, 29,(1), 26-28.

Gudykunst, W. B., Hammer, M. R. \& Wiseman, R. (1977). An analysis of an integrated approach to cross-cultural training. International Journal of Intercultural Relations. 1, 99-110. 
Hall, E. T. (1981). Beyond Culture. New York: Doubleday.Huntington. S. P. (1993). The New York Times. vl42 4 pE19(N) p E19(L) col 1 (50 col in).

Johnson, R. (1992). Diversity training: Integral steps for bridging race, language, gender gaps. Training, 29, (7), B01-B04.

Johnson, R. B. \& O'Mara, J. (1992). Shedding new light on diversity training. Training \& Development, $46(5), 44-52$.

Kohls, L. R. (1979). Cross-cultural trainers' needs for supporting research and materials development. In Intercultural Theory and Practice: Perspectives on Education. Training and Research. Ed. W. G. Gavey. La Grange Park, Illinois: Intercultural Network, Inc.

Korzybski, A. (1933). Science and sanity: An introduction to non-aristotelian systems and general semantics. Lakeville, Connecticut: The International Library Publishing Co.

Kraiger, K., Ford, J. K. \& Salas, E. (1993). Application of cognitive, skill-based, and affective theories of learning outcomes to new methods of training evaluation. Journal of Applied Psychology. 78(2), 311-328.

Lalonde, R. N. \& Cameron, J. E. (1994). Behavioral responses to discrimination: a focus on action. in The Psychology of Prejudice edited by Zanna, M. P. \& Olson, J. M. Hillsdale, NJ: Lawrence Erlbaum Associates, Publishers.

Lieberman, D. (1994). Train-the-Trainer Cultural Diversity Workbook.

Mayer, R. J. (1989). Conflict Management: The Courage to Confront. Columbus: Battelle Press.

McDiarmid, G. W. (1992). What to do about differences? A study of multicultural education for teacher trainees in the Los Angeles Unified School District. Journal of Teacher Education, 43(2), 83-94.

Miller, D. C. (1991). Handbook of Research Design and Social Measurement, $5^{\text {th }}$ Ed. Newbury Park: Sage Publications.

Mobley, M. \& Payne, T. (1992). Backlash! The challenge to diversity training. Training \& Development, $\underline{46}(12), 45-52$. 
Morrison, A. M. \& Crabtree, K. M. (1994). Developing Diversity in Organizations:

A Digest of Selected Literature. Greensboro: Center for Creative Leadership.

Mortensen, C. D. (1972). Communication: The Study of Human Interaction. New York: McGraw-Hill Book Company.

Murray, K. (1993). The unfortunate side effects of 'diversity training'. The New York Times, August 1, v142 s3 pF5(N) pF5(L) col 1 (31 col in).

Nishishiba, M. (1994). Reading and conference data analysis graduate project. Patton, M. Q. (1990). Qualitative evaluation and research methods. Newbury Park: Sage Publications.

Payne, T. \& Mobley, M. (1992). Backlash! The challenge to diversity training. Training \& Development. Dec. p. 45-52.

Pickard, J. (1991). Steel partners. Personnel Management. 23, (12), 32-34.Pool, I. DeS. (ed.) (1959). Trends in Content Analysis. Urbana: University of Illinois Press.

Pusch, M. D. (1979). Multicultural Education: A Cross Cultural Training Approach. NY: Intercultural Press.

Samovar, L. A. \& Porter, R. E. (1991). Communication Between Cultures. Belmont: Wadsworth Publishing Company.

Saslow, C. A. (1982). Basic Research Methods. Menlo Park: Addison-Wesley Publishing Company.

Schaffer, R. H. \& Thomson, H. A. (1992). Successful change programs begin with results. Harvard Business Review, Jan-Feb, 80-89.

Shelton, S. \& Alliger, G. (1993). Who's afraid of level 4 evaluation? A practical approach. Training \& Development. 47(6), 43-47.

Sowell, T. (1993). Effrontery and gall, Inc. Forbes 152(7), 52.Steinburg, C. (1991). Diversity training goes to court. Training \& Development, 4 5(11), 11-13.

Steinburg, C. (1992). Self-awareness on patrol. Training \& Development, 46(11) 911.

Strauss, A \& Corbin, J. (1990). Basics of Qualitative Research. Newbury Park: SAGE Publications, Inc. 
Tannenbaum, S. I. \& Woods, S. B. (1992). Determining a strategy for evaluating training: Operating within organizational constraints. Human Resource Planning, 15(2), 63-80.

Taylor, S. J. \& Bogdam, R. (1984). Introduction to Qualitative Research Methods. New York: John Wiley \& Sons.

Thomas Jr., R. R. (1990). From affirmative action to affirming diversity. Harvard Business Review. March-April, p. 107-117.

Trenholm, S. (1989). Persuasion and Social Influence. Englewood Cliffs: Prentice Hall.

Triandis, H. C. (1977). Theoretical framework for evaluation of cross-cultural training effectiveness. International Journal of Intercultural Relations. Winter, 19-44.

van de Vliet, A. (1993). Assess for success. Management Today. July, 60-64.

Watson, D. L. \& Tharp, R. G. (1989). Self-Directed Behavior. Pacific Grove: Brooks/Cole Publishing Company.

Wigglesworth, D. C. (1992). Video-ing diversity: A review of training videos on workforce diversity. Training \& Development, $46(12), 53-58$.

Wile, D. B. (1988). After the honeymoon: How conflict can improve your relationship. NY: John Wiley \& Sons, Inc.

Winkelman, M. (1993). Ethnic relations in the U.S. St. Paul, MN: West.

Woolsey, L. K. (1986). The critical incident technique: an innovative qualitative method of research. Canadian Journal of Counseling, 20, (4) 242-254. 


\section{APPENDIX A}

Diversity Questionnaire - Workshop questionnaire 
Diversity Workshop questionnaire

PLEASE COMPLETE THE FOLLOWING QUESTIONS. DO NOT PUT YOUR NAME ON THIS QUESTIONNAIRE. FEEL FREE TO USE THE BACK IF YOU WISH.

1. Think of a situation you have been in when someone else made a comment or exhibited a behavior that you thought was discriminatory (e.g., racist, ageist, sexist, etc.).

a. What was the relationship between you and the other person?

b. What was the situation?

c. What did the person say or behavior exhibited?

d. What did you say or do at the time?

2. If you thought about the situation later...

a. What did you think?

b. How did you feel?

3. What could you have said or done differently in that situation?

4. What is your gender?

5. What is your age?

6. What is your ethnic/cultural background? 
APPENDIX B

Typology - Pilot Study 
Typology - Pilot Study

\begin{tabular}{|l|c|c|c|c|c|c|c|}
\hline \multicolumn{3}{|c|}{ Verbal Interactive } & \multicolumn{2}{c|}{ Physical Interactive } & Non-Interactive \\
\hline $\begin{array}{l}\text { Change } \\
\text { Subject }\end{array}$ & $\begin{array}{c}\text { Asked } \\
\text { Question }\end{array}$ & Disagree & $\begin{array}{c}\text { Explain } \\
\text { Point of } \\
\text { View }\end{array}$ & Contact & No Contact & Ignored & Leave Scene \\
\hline
\end{tabular}




\section{APPENDIX C}

Sample Data 


\begin{tabular}{|c|c|c|c|c|c|c|c|c|c|c|}
\hline $\begin{array}{l}N \\
0 .\end{array}$ & $\begin{array}{l}\text { PRETEST } \\
\text { Relalionship }\end{array}$ & Siluation & $\begin{array}{l}\text { What Did They Say } \\
\text { Behavior }\end{array}$ & $\begin{array}{l}\text { What Did You Say or Do } \\
\text { at the Time? }\end{array}$ & $\begin{array}{l}\text { If you thought about } \\
\text { the situation laler... } \\
\text { What Did You Think? }\end{array}$ & $\begin{array}{l}\text { How Did You } \\
\text { Feal? }\end{array}$ & $\begin{array}{l}\text { What Could } \\
\text { You Havo } \\
\text { Sald/Done Diff }\end{array}$ & $\begin{array}{l}M / \\
F\end{array}$ & ${ }_{\theta}^{A g}$ & $\begin{array}{l}\text { Ethnid } \\
\text { Cultur } \\
e \\
\end{array}$ \\
\hline 12 & $\begin{array}{l}\text { Casual } \\
\text { acquaintance }\end{array}$ & $\begin{array}{l}\text { At a party \& this } \\
\text { person told a racial } \\
\text { joke about Hispanics }\end{array}$ & Told the joke & $\begin{array}{l}\text { Tlooked at him \& said I } \\
\text { am Hispanic \& don't find } \\
\text { the joke funny }\end{array}$ & & $\begin{array}{l}\text { Normally this } \\
\text { doesn't bolther } \\
\text { me - But I } \\
\text { didn't like the } \\
\text { person's } \\
\text { attitude at all } \\
\text { (Ihis is also } \\
\text { not good on } \\
\text { my part) - } 10 \\
\text { not like him. }\end{array}$ & $\begin{array}{l}\text { Nothing - I } \\
\text { foel I handled } \\
\text { II correcily. }\end{array}$ & $F$ & 42 & $\begin{array}{l}\text { Hispa } \\
\text { nic }\end{array}$ \\
\hline 13 & Co. worker & $\begin{array}{l}\text { During work day } \\
\text { discussions }\end{array}$ & Elhnic slurs & Smiled at Co-worker & Wrong lining lo do & & $\begin{array}{l}\text { Probably } \\
\text { nothing as } \\
\text { Co- worker } \\
\text { just made the } \\
\text { statement }\end{array}$ & $\bar{M}$ & 44 & $\begin{array}{l}\text { while } \\
\text { baldin } \\
\text { g male }\end{array}$ \\
\hline 14 & $\begin{array}{l}\text { In the same } \\
\text { training class }\end{array}$ & Training & $\begin{array}{l}\text { Not willing to listen to } \\
\text { terms used in every } \\
\text { day talk - bitching. } \\
\text { chief }\end{array}$ & nothing & $\begin{array}{l}\text { That this person was } \\
\text { showing the same } \\
\text { behavior that she } \\
\text { complained about }\end{array}$ & $\begin{array}{l}\text { Thal she took } \\
\text { away from the } \\
\text { training by } \\
\text { inhibiting the } \\
\text { free now of } \\
\text { speech }\end{array}$ & $\begin{array}{l}\text { Volced my } \\
\text { own feelings }\end{array}$ & $\bar{M}$ & 58 & White \\
\hline 15 & $\begin{array}{l}\text { Employes of } \\
\text { the same } \\
\text { agency but } \\
\text { from another } \\
\text { office }\end{array}$ & In a training seminar & $\begin{array}{l}\text { Lumped all from an } \\
\text { ethnle group Into one } \\
\text { category. Rather } \\
\text { lhan each as a } \\
\text { person }\end{array}$ & $\begin{array}{l}\text { Pointed out that I was } \\
\text { from that ethnic group } \\
\text { and my qualifications \& } \\
\text { experlence were better } \\
\text { than his }\end{array}$ & $\begin{array}{l}\text { T considered the } \\
\text { source and forgol } \\
\text { aboul it }\end{array}$ & $O K$ & Nothing & $\bar{M}$ & 49 & $\begin{array}{l}\text { Hispa } \\
\text { nic }\end{array}$ \\
\hline 16 & None & $\begin{array}{l}\text { Walked into a } \\
\text { restaurant with my } \\
\text { nephew's children } \\
\text { who are Hispanlc } \\
\end{array}$ & $\begin{array}{l}\text { Icy looks from other } \\
\text { "guests" }\end{array}$ & nothing & $\begin{array}{l}\text { how dumb, gross } \\
\text { slupidity }\end{array}$ & pissed & $?$ & $\bar{M}$ & $5 \overline{5 \varepsilon}$ & WASP \\
\hline 17 & None & $\begin{array}{l}\text { Group lalking } \\
\text { lagether (BS) }\end{array}$ & $\begin{array}{l}\text { Disrespectiul \& ( ) } \\
\text { jokes about his } \\
\text { girlifiend }\end{array}$ & Tleft group & $\begin{array}{l}\text { He has a lot to learn } \\
\text { aboul other people. } \\
\text { How would he feel if } \\
\text { he found out that joke } \\
\text { \& bad remarks were } \\
\text { said about him }\end{array}$ & $\begin{array}{l}\text { Angry and } \\
\text { sad that we } \\
\text { have people } \\
\text { stupld in our } \\
\text { society }\end{array}$ & $\begin{array}{l}\text { Without } \\
\text { getting on a } \\
\text { soap box. } \\
\text { probably } \\
\text { nothing, I } \\
\text { didn't know } \\
\text { him and } \\
\text { barely know } \\
\text { some of the } \\
\text { group }\end{array}$ & $M$ & 47 & $\begin{array}{l}\text { Hispa } \\
\text { nlc }\end{array}$ \\
\hline 18 & Coworker & $\begin{array}{l}\text { Toverheard a remark } \\
\text { that was not directed } \\
\text { to me }\end{array}$ & $\begin{array}{l}\text { The woman made a } \\
\text { remark about men }\end{array}$ & nothing & $\begin{array}{l}\text { am used to the } \\
\text { banter and the men } \\
\text { who know her are } \\
\text { used to lt and respond } \\
\text { in spirit }\end{array}$ & $\begin{array}{l}\text { I'm not } \\
\text { comfortable } \\
\text { but if doesn't } \\
\text { bother me } \\
\text { enough to } \\
\text { ining about it }\end{array}$ & $\begin{array}{l}\text { If I had } \\
\text { responded I } \\
\text { would expect } \\
\text { to be told to } \\
\text { lighten up }\end{array}$ & $F$ & 51 & $\begin{array}{l}\text { White } \\
\text { Northe } \\
\text { rn } \\
\text { Europ } \\
\text { ean } \\
\text { Ancest } \\
\text { y }\end{array}$ \\
\hline
\end{tabular}




\begin{tabular}{|c|c|c|c|c|c|c|c|c|c|c|}
\hline $\begin{array}{l}N \\
0 .\end{array}$ & $\begin{array}{l}\text { PRETEST } \\
\text { Rolationship }\end{array}$ & Situation & $\begin{array}{l}\text { What Dld They Say } \\
\text { Behavior }\end{array}$ & $\begin{array}{l}\text { What Did You Sey or Do } \\
\text { ot the Time? }\end{array}$ & $\begin{array}{l}\text { If you thought about } \\
\text { the siturition later... } \\
\text { Whet Did You Think? }\end{array}$ & $\begin{array}{l}\text { How Did You } \\
\text { Feel? }\end{array}$ & $\begin{array}{l}\text { What Could } \\
\text { You Have } \\
\text { SaldDone Dif }\end{array}$ & $\stackrel{M}{F}$ & $\begin{array}{l}A g \\
\theta\end{array}$ & $\begin{array}{l}\text { Ethnid } \\
\text { Cultur } \\
\theta \\
\end{array}$ \\
\hline 7 & My doctor & $\begin{array}{l}\text { I was being treated } \\
\text { for "Being tired a lot" } \\
\text { - Ended up as a lung } \\
\text { disorder }\end{array}$ & $\begin{array}{l}\text { "Don't you think you } \\
\text { are a little odd to be } \\
\text { running } 3 \text { times a day. } \\
\text { working full time and } \\
\text { going to night school }\end{array}$ & No & $\begin{array}{l}\text { Thad been pre } \\
\text { as sessed or } \\
\text { calegorized as "odd" }\end{array}$ & $\begin{array}{l}\text { Anger. } \\
\text { Frustration }\end{array}$ & $\begin{array}{l}\text { We had words } \\
\text { that cleared } \\
\text { the air } \& \text { got } \\
\text { both of us } \\
\text { bock on a } \\
\text { professlonal } \\
\text { track. I lika } \\
\text { dealing wilh } \\
\text { situations "up } \\
\text { fronl" and } \\
\text { "now." I'm stills } \\
\text { salisfied with } \\
\text { the way. } \\
\text { handled it } 14 \\
\text { years later. }\end{array}$ & $\bar{M}$ & 48 & White \\
\hline 8 & Co-worker & Told a joke & Told a joke & semi laughed & $\begin{array}{l}\text { Thal the person is } \\
\text { prejudiced }\end{array}$ & $\begin{array}{l}\text { Awkward and } \\
\text { guilty for } \\
\text { laughing or } \\
\text { seeming to } \\
\text { appreciate the } \\
\text { joke }\end{array}$ & not laughed & $M$ & 46 & White \\
\hline$\overline{9}$ & $\begin{array}{l}\text { Manager/Empl } \\
\text { oyse }\end{array}$ & $\begin{array}{l}\text { Non-Work related } \\
\text { discussion }\end{array}$ & $\begin{array}{l}\text { Told slory about a } \\
\text { friend who bold thls } \\
\text { person about these } \\
\text { plittle bleck boys in } \\
\text { Alabama". complete } \\
\text { with Southern accent. }\end{array}$ & Stayed Silent & $\begin{array}{l}\text { Trell fit continued } \\
\text { erroneous \& } \\
\text { prejudicial ideas of } \\
\text { what a certain group's } \\
\text { characteristics }\end{array}$ & $\begin{array}{l}\text { Tfelt like I } \\
\text { should say } \\
\text { somemethlng but } \\
\text { dldn't want } 10 \\
\text { appear critical } \\
\text { of the } \\
\text { manager or } \\
\text { bring even } \\
\text { more } \\
\text { attention } 10 \\
\text { the story }\end{array}$ & $\begin{array}{l}\text { Made a } \\
\text { statement to } \\
\text { the effect that } \\
\text { this was } \\
\text { continuing } \\
\text { prejudicial } \\
\text { perceptions of } \\
\text { a group of } \\
\text { people. }\end{array}$ & $\bar{F}$ & 48 & $\begin{array}{l}\text { Bohe } \\
\text { mlan, } \\
\text { Canad } \\
\text { lan- } \\
\text { Frenc } \\
h \text {. } \\
\text { Indian, } \\
\text { Scottis } \\
h \\
\text { Cauca } \\
\text { sian } \\
\end{array}$ \\
\hline 10 & God parents & $\begin{array}{l}\text { They told a black } \\
\text { joke }\end{array}$ & $\begin{array}{l}\text { Made fun of the black } \\
\text { people }\end{array}$ & didn't laugh & $\begin{array}{l}\text { Couldn't believe they } \\
\text { would tell a joke like } \\
\text { that }\end{array}$ & $\begin{array}{l}\text { Upsel at them } \\
\text { \& surprised }\end{array}$ & Nothing & $F$ & 45 & $\begin{array}{l}\text { White } \\
\text { (Englis } \\
h \text {. } \\
\text { Germa } \\
n \& \\
\text { Hunga } \\
\text { rian }\end{array}$ \\
\hline$\overline{11}$ & $\begin{array}{l}\text { To nol wish } \\
\text { to share my } \\
\text { past } \\
\text { experiences }\end{array}$ & & & & & & & & & \\
\hline
\end{tabular}




\begin{tabular}{|c|c|c|c|c|c|c|c|c|c|c|}
\hline $\begin{array}{l}N \\
0 .\end{array}$ & $\begin{array}{l}\text { PRETEST } \\
\text { Relationship }\end{array}$ & Situation & $\begin{array}{l}\text { What Did They Say } \\
\text { Behavior }\end{array}$ & $\begin{array}{l}\text { What Did You Say or Do } \\
\text { af the Time? }\end{array}$ & $\begin{array}{l}\text { If you thought sbout } \\
\text { the situation laler... } \\
\text { What Did You Think? }\end{array}$ & $\begin{array}{l}\text { How Did You } \\
\text { Foel? }\end{array}$ & $\begin{array}{l}\text { What Could } \\
\text { You Have } \\
\text { SaidDone Dith }\end{array}$ & $\begin{array}{l}M \prime \\
F\end{array}$ & $\underset{\theta}{A g}$ & $\begin{array}{l}\text { Elthnic } \\
\text { Cultur } \\
e\end{array}$ \\
\hline 1 & $\begin{array}{l}\text { Customer \& } \\
\text { Worker }\end{array}$ & $\begin{array}{l}\text { Customer wanting } \\
\text { info on an out of } \\
\text { state claim }\end{array}$ & $\begin{array}{l}\text { He was very obstinate } \\
\& \text { couldn't } \\
\text { communicate with } \\
\text { him. He became very } \\
\text { angry. }\end{array}$ & $\begin{array}{l}\text { Keep tring to explain \& } \\
\text { reason with him but he } \\
\text { wouldn't listen. Asked if } \\
\text { he wanted a supervisor. }\end{array}$ & $\begin{array}{l}\text { If felt he was really } \\
\text { angry \& upset but! } \\
\text { wasn't sure why. }\end{array}$ & Upset & $?$ & $F$ & 50 & \\
\hline$\overline{2}$ & $\begin{array}{l}\text { Outside } \\
\text { Employer }\end{array}$ & $\begin{array}{l}\text { Wanted references } \\
\text { for a bartender }\end{array}$ & $\begin{array}{l}\text { Stated "Don't send } \\
\text { any old broads or fal } \\
\text { chicks" }\end{array}$ & $\begin{array}{l}\text { Advised him of } \\
\text { discrimination laws }\end{array}$ & $\begin{array}{l}\text { Individual set in his } \\
\text { ways and looking at } \\
\text { people only from } \\
\text { oulside appearance. }\end{array}$ & $\begin{array}{l}\text { That this } \\
\text { person had a } \\
\text { limited point } \\
\text { of view }\end{array}$ & Nothing & $M$ & 46 & $\begin{array}{l}\text { Cauca } \\
\text { sian }\end{array}$ \\
\hline 3 & $\begin{array}{l}\text { Pro at the Golf } \\
\text { Course }\end{array}$ & $\begin{array}{l}\text { A goll club left in the } \\
\text { pro-shop the check } \\
\text { hadn't cleared. } \\
\text { belonged to a tall } \\
\text { black man }\end{array}$ & $\begin{array}{l}\text { Assumption that all } \\
\text { tall black men are the } \\
\text { same person }\end{array}$ & $\begin{array}{l}\text { Do you think all black } \\
\text { men have the same Bank } \\
\text { of Africa? I embarrassed } \\
\text { them. }\end{array}$ & $\begin{array}{l}\text { I thought insensitive \& } \\
\text { not very intelligent } \\
\text { uneducated }\end{array}$ & Good! & Nolhing & $\mathrm{F}$ & 55 & \\
\hline 4 & Co-Worker & $\begin{array}{l}\text { The co-worker foll } \\
\text { she was being } \\
\text { "plcked on" about } \\
\text { her work habits - sho } \\
\text { attributed this to her } \\
\text { race. }\end{array}$ & $\begin{array}{l}\text { She said that if she } \\
\text { were another race } \\
\text { this probably wouldn't } \\
\text { happen end she } \\
\text { acted very nasty. }\end{array}$ & $\begin{array}{l}\text { Nol much - the more the } \\
\text { co-workers tried to reclify } \\
\text { the problem the worse it } \\
\text { got }\end{array}$ & $\begin{array}{l}\text { It was too bad } \\
\text { because I never } \\
\text { considered her skin } \\
\text { color - I did consider } \\
\text { her a friend }\end{array}$ & $\begin{array}{l}\text { I wish she } \\
\text { could not } \\
\text { have been so } \\
\text { sensitive. I } \\
\text { do leel she } \\
\text { was very } \\
\text { sensitive to } \\
\text { the matter. }\end{array}$ & Nol sure & $F$ & 41 & $\begin{array}{l}\text { Cauca } \\
\text { sian }\end{array}$ \\
\hline 5 & $\begin{array}{l}\text { 1- Customer } \\
\text { Other. } \\
\text { Service } \\
\text { provider }\end{array}$ & $\begin{array}{l}\text { T. member of an } \\
\text { organizatlon, was } \\
\text { asked to show l.D. : } \\
\text { others, as they } \\
\text { entered, were not }\end{array}$ & Beg above & showed 1.0 & $\begin{array}{l}\text { Only difference } \\
\text { between myself and } \\
\text { others members, was } \\
\text { the color of my skin }\end{array}$ & $\begin{array}{l}\text { Angry - due to } \\
\text { what I feel } \\
\text { was the } \\
\text { obvious } \\
\text { racism. }\end{array}$ & $\begin{array}{l}\text { T showed my } \\
\text { l.D., asked } \\
\text { nothing, sald } \\
\text { nothing. } \\
\text { NOTE: } \\
\text { Community in } \\
\text { which I live } \\
\text { has many, } \\
\text { many racial } \\
\text { problems. } \\
\text { What I } \\
\text { described was } \\
\text { a very minor } \\
\text { incident. I } \\
\text { also wrote a } \\
\text { letter to the } \\
\text { president at } \\
\text { lhe } \\
\text { organization } \\
\text { re incident, } \\
\text { and received } \\
\text { an apologyl }\end{array}$ & $\bar{M}$ & 45 & $\begin{array}{l}\text { Ameri } \\
\text { can - } \\
\text { Hispa } \\
\text { nic } \\
\text { origin }\end{array}$ \\
\hline 8 & Acquaintance & Conversation & $\begin{array}{l}\text { Mentioned that white } \\
\text { people are prejudiced }\end{array}$ & Smiled & In appropriate & Confused & $?$ & $\bar{M}$ & 45 & White \\
\hline
\end{tabular}




\section{APPENDIX D}

Description of the Diversity Training Program Analyzed in this Study 
Description of the Diversity Training Program Analyzed in this Study Program Design

During the summer of 1993, Devorah Lieberman, Ph.D. designed and implemented a "train-the-trainer" (Lieberman, 1994) diversity training program for a state level organization. The program was implemented in a two phase sequence. During Phase I, Lieberman provided a three week training workshop to individuals who volunteered from throughout the organization. These individuals were selected by a diversity team appointed by the organization director to later provide diversity training for the rest of the 1200 employees in the organization. During Phase II, these individuals paired up in dyads to provide one day workshops on cultural diversity for the organization. In this way, the entire organization received cultural diversity training.

During Phase I, Lieberman (principle trainer/consultant) taught the theoretical underpinnings regarding cultural diversity, provided opportunities to practice facilitation skills needed to present cultural diversity workshops and encouraged participants to incorporate what they learned during training into their daily lives. During the first week, participants were taught intercultural theory and facilitation skills, participated in structured exercises, and practiced presenting intercultural information in dyad form. Materials provided by the consultant included an Intercultural Communication textbook with instructor's manual, a train-the-trainer notebook for participant employees to use during the week-long training, and a facilitator's guide providing instruction about the dissemination of theory and leading structured exercises.

During the next two weeks, each trainee dyad presented one four hour practice mini-workshop on cultural diversity to groups of six to ten employees. Dyads repeated 
the mini-workshops as needed until all dyads received passing scores on intercultural communication and facilitation effectiveness from the principle trainer or the trainer's assistant. Following the mini-workshops, the principle trainer demonstrated the oneday workshop to all Phase I participants and also provided the one-day workshop to the managerial level of the state organization.

During Phase II, participants from the initial training group provided one-day workshops for the other 1200 employees in the organization. The consultant provided a participant's guide which would be used by all employees taking the day-long workshop. At the beginning of each one-day workshop, employee participants completed the workshop questionnaire evaluation instrument designed by Lieberman. Within six months, one-day workshop participants were contacted through mail by the head of the diversity team, Celina Ratliff, and asked to complete a second questionnaire, a posttest measure. Approximately twelve hundred employees attended the one-day workshop.

\section{Training Goals}

An interview with the trainer (personal communication, Lieberman, February, 1994) revealed the following training goals for the participants:

1) Increase in personal awareness - greater understanding of self in the workplace;

2) Greater understanding of their place in the workplace - how they fit in the scheme;

3) Understanding their personal behaviors in relation to their culture and co-cultures;

4) Recognize and reduce their own prejudices;

5) Learn new behaviors to replace old behaviors;

6) Educate others to be less discriminatory. 


\section{Training Objectives}

In support of the overall training goals, Lieberman listed the following overall project objectives in the training guide for both the Phase I and Phase II training recipients:

1. recognize the benefits of cultural, ethnic, gender, socio-economic, political, religious and personality diversity within the workplace;

2. identify personal value/belief/attitude systems from a culture general perspective and a culture specific perspective;

a. understand the basic value differences among: polychronic and monochronic time orientations, power and authority issues, higher context and lower context communication, individualistic and collectivistic perceptions of one's role/place in an organization/team;

3. identify nonverbal communication considerations in an intercultural interaction: movement, touch, conversation regulators, distance, eye contact, voice, dress and time

4. recognize one's own ethnocentric tendencies;

5. apply particular strategies to understand differences in behavior and cultural philosophies and encourage team work or improved customer interaction;

6. apply culturally sensitive communication strategies to reduce potential intercultural conflicts or misunderstandings;

7. apply communication strategies to reduce intentional and unintentional discriminatory behaviors exhibited within the workplace;

8. be culturally sensitive as well as encouraging teamwork when interacting on a team project or within department meetings. 
The selection of these particular goals and objectives reflect values the trainer wished to address in the workshop, such as increasing cultural sensitivity and understanding, reducing discrimination, and providing tools for dealing with discrimination. In fact, the program description outlines three areas upon which the workshops focus,

1) understanding the importance of diversity within the workplace;

2) addressing specific strategies which enhance intercultural communication among employees and between employees and customers; and ,

3) educating others to be more interculturally sensitive.

Implicit in these areas is the trainer's intention (Lieberman, personal correspondence) to impact participants on several levels, including awareness knowledge, feelings, understanding, behavior, attitudes, skills, ability to empathize, and perception. The impacts intended by the trainer include all five of the possible effects upon learners listed by Pusch as knowledge, perceptions, attitudes, skills and patterns of behavior. A review of the training guides suggests that in order to impact these five areas, the trainer utilizes an approach which integrates information and skills and uses both cognitive and affective techniques. Thus, the trainer takes a holistic approach to learning by addressing the many ways a learner has of processing information. 